OPEN ACCESS

Edited by:

Sabrina Büttner,

Stockholm University, Sweden

Reviewed by:

Martin Lothar Duennwald, University of Western Ontario,

Canada

Bing Zhou,

Tsinghua University, China

*Correspondence: Gerhard H. Braus gbraus@gwdg.de

Received: 13 December 2017 Accepted: 09 March 2018 Published: 27 March 2018

Citation:

Popova B, Kleinknecht A, Arendarski P, Mischke J, Wang D and Braus GH (2018) Sumoylation Protects Against $\beta$-Synuclein Toxicity in Yeast.

Front. Mol. Neurosci. 11:94 doi: 10.3389/fnmol.2018.00094

\section{Sumoylation Protects Against $\beta$-Synuclein Toxicity in Yeast}

\author{
Blagovesta Popova ${ }^{1,2}$, Alexandra Kleinknecht ${ }^{1,2}$, Patricia Arendarski ${ }^{1}$, Jasmin Mischke ${ }^{1}$, \\ Dan Wang ${ }^{1}$ and Gerhard H. Braus ${ }^{1,2 *}$
}

${ }^{1}$ Department of Molecular Microbiology and Genetics and Göttingen Center for Molecular Biosciences (GZMB), Institute for Microbiology and Genetics, Universität Göttingen, Göttingen, Germany, ${ }^{2}$ Center for Nanoscale Microscopy and Molecular Physiology of the Brain (CNMPB), Göttingen, Germany

Aggregation of $\alpha$-synuclein ( $\alpha$ Syn) plays a central role in the pathogenesis of Parkinson's disease (PD). The budding yeast Saccharomyces cerevisiae serves as reference cell to study the interplay between $\alpha$ Syn misfolding, cytotoxicity and post-translational modifications (PTMs). The synuclein family includes $\alpha, \beta$ and $\gamma$ isoforms. $\beta$-synuclein ( $\beta$ Syn) and $\alpha$ Syn are found at presynaptic terminals and both proteins are presumably involved in disease pathogenesis. Similar to $\alpha$ Syn, expression of $\beta$ Syn leads to growth deficiency and formation of intracellular aggregates in yeast. Co-expression of $\alpha$ Syn and $\beta$ Syn exacerbates the cytotoxicity. This suggests an important role of $\beta$ Syn homeostasis in PD pathology. We show here that the small ubiquitin-like modifier SUMO is an important determinant of protein stability and $\beta$ Syn-induced toxicity in eukaryotic cells. Downregulation of sumoylation in a yeast strain, defective for the SUMO-encoding gene resulted in reduced yeast growth, whereas upregulation of sumoylation rescued growth of yeast cell expressing $\beta S y n$. This corroborates a protective role of the cellular sumoylation machinery against $\beta$ Syn-induced toxicity. Upregulation of sumoylation significantly reduced $\beta$ Syn aggregate formation. This is an indirect molecular process, which is not directly linked to $\beta$ Syn sumoylation because amino acid substitutions in the lysine residues required for $\beta$ Syn sumoylation decreased aggregation without changing yeast cellular toxicity. $\alpha$ Syn aggregates are more predominantly degraded by the autophagy/vacuole than by the 26S ubiquitin proteasome system. We demonstrate a vice versa situation for $\beta S y n$, which is mainly degraded in the $26 S$ proteasome. Downregulation of sumoylation significantly compromised the clearance of $\beta$ Syn by the $26 S$ proteasome and increased protein stability. This effect is specific, because depletion of functional SUMO did neither affect $\beta$ Syn aggregate formation nor its degradation by the autophagy/vacuolar pathway. Our data support that cellular $\beta$ Syn toxicity and aggregation do not correlate in their cellular impact as for $\alpha$ Syn but rather represent two distinct independent molecular functions and molecular mechanisms. These insights into the relationship between $\beta$ Syn-induced toxicity, aggregate formation and degradation demonstrate a significant distinction between the impact of $\alpha$ Syn compared to $\beta$ Syn on eukaryotic cells.

Keywords: beta-synuclein, Parkinson's disease, sumoylation, posttranslational modification, yeast, proteasome, autophagy, aggregation 


\section{INTRODUCTION}

Parkinson's disease (PD) is characterized by loss of dopaminergic neurons in the substantia nigra in the midbrain and formation of intracellular protein inclusions called Lewy bodies (Kalia and Lang, 2015). Loss of dopaminergic neurons leads to dopamine depletion and results in a wide range of motoric and non-motoric symptoms. One of the major components of Lewy bodies is the small and highly abundant protein $\alpha$-synuclein ( $\alpha$ Syn; Spillantini et al., 1998). $\alpha$ Syn is part of a family of proteins that includes also $\beta$-synuclein ( $\beta$ Syn) and $\gamma$-synuclein $(\gamma$ Syn $), \alpha$ Syn and $\beta$ Syn are localized predominantly at presynaptic nerve terminals, whereas $\gamma$ Syn is abundant in the peripheral nervous system ( $\mathrm{Li}$ et al., 2002; Mori et al., 2002). Synuclein family members share a highly conserved $\mathrm{N}$-terminal domain and a more divergent and highly acidic C-terminal domain. $\alpha$ Syn and $\beta$ Syn are closely related to each other and their sequences share 62\% homology (George, 2002). The most notable difference between the two proteins is that $\beta$ Syn lacks 11 residues in the central most hydrophobic region, referred to as non-amyloid- $\beta$ component (NAC) region, involved in fibril formation and aggregation. All three synucleins are intrinsically unstructured when isolated under physiological conditions and adopt helical structures in their N-terminal domains upon binding to lipid vesicles (Sung and Eliezer, 2006; Ducas and Rhoades, 2012).

$\alpha$ Syn is implicated as prime contributor of PD development as it is associated with familial and sporadic forms of PD. The protein has a strong propensity to self-assemble into oligomeric protofibrils that can further mature into different types of fibrils and insoluble aggregates (Villar-Piqué et al., 2015). The abnormal accumulation of the protein is partly triggered by gene duplications or even triplications as well as missense mutations (Polymeropoulos et al., 1997; Krüger et al., 1998; Singleton et al., 2003; Zarranz et al., 2004). Aggregation of $\alpha$ Syn is assumed to constitute the central pathological process in synucleinopathies. One of the critical factors that affect $\alpha$ Syn aggregation process is the protein level in the cell, which depends on the rate of its turnover. $\alpha$ Syn can be degraded both by ubiquitin-proteasome system (UPS) and the autophagy/lysosome pathway (Webb et al., 2003; Xilouri et al., 2013). Inhibition of protein degradation pathways resulting in inefficient protein clearance leads to accumulation of pathological $\alpha$ Syn species and is sufficient to trigger neurotoxicity (Xilouri et al., 2013; Vilchez et al., 2014). Therefore, understanding of $\alpha$ Syn turnover mechanism is an essential aspect to uncover the pathological mechanism of PD.

$\alpha$ Syn undergoes numerous post-translational modifications (PTMs) such as phosphorylation, ubiquitination, sumoylation, nitration or acetylation (Giasson et al., 2000; Shimura et al., 2001; Fujiwara et al., 2002; Hasegawa et al., 2002; Dorval and Fraser, 2006; Kleinknecht et al., 2016; de Oliveira et al., 2017). PTMs influence $\alpha$ Syn aggregation and toxicity and in addition modulate the degradation of the protein by different proteolytic pathways (Popova et al., 2015). The small ubiquitin-like modifier SUMO is covalently conjugated to target proteins and modulates a number of cellular processes. Many $\mathrm{PD}$-associated proteins are SUMO-modified, highlighting the importance of this PTM in neurodegeneration (Eckermann, 2013). $\alpha$ Syn is a substrate of SUMO1, one of the four SUMO isoforms in human (Dorval and Fraser, 2006). Sumoylation of $\alpha$ Syn negatively regulates $\alpha$ Syn aggregation by promoting protein solubility (Krumova et al., 2011).

The yeast Saccharomyces cerevisiae is a valuable model system for studying protein misfolding and cellular pathways associated with protein quality control systems due to the high conservation of functions with higher eukaryotes including humans (Menezes et al., 2015). Heterologous expression of $\alpha$ Syn in yeast results in aggregate formation and dose-dependent cytotoxicity, recapitulating central features of PD (Outeiro and Lindquist, 2003; Petroi et al., 2012). Yeast was employed to investigate the role of PTMs for $\alpha$ Syn aggregate clearance. Recent study demonstrated that $\alpha$ Syn is sumoylated in yeast and that the cellular mechanism of sumoylation is conserved from yeast to human (Shahpasandzadeh et al., 2014). The distribution of $\alpha$ Syn to different cellular degradation pathways was dependent on a complex cross-talk between sumoylation and phosphorylation at Serine 129 (S129).

The other two members of synuclein family have been less well studied until recently due to lack of genetic links to PD. Initial reports suggested $\beta$ Syn as a negative regulator of $\alpha$ Syn aggregation (Hashimoto et al., 2001; Uversky et al., 2002; Fan et al., 2006). Recent results revealed that $\beta$ Syn can act as a neurodegeneration-inducing factor and can cause cell loss when expressed in rat brains (Taschenberger et al., 2013). This suggests a role of $\beta$ Syn in the pathogenesis of PD. V70M or $\mathrm{P} 123 \mathrm{H}$ mutations in $\beta$ Syn were linked to cases of dementia with Lewy bodies (DLB; Ohtake et al., 2004) and were suggested to be involved in lysosomal pathology (Wei et al., 2007). Expression of $\mathrm{P} 123 \mathrm{H} \beta$ Syn in transgenic mouse resulted in progressive neurodegeneration that acted synergistically with overexpression of $\alpha$ Syn (Fujita et al., 2010). These studies revealed an emerging role of $\beta$ Syn in a broad range of $\alpha$-synucleinopathies. However, the molecular mechanism of this role remains poorly studied.

Recently, yeast was used as a reference cell to investigate the cellular effects of $\beta$ Syn. Expression of $\beta$ Syn but not $\gamma$ Syn was toxic to yeast cells and resulted in formation of cytosolic inclusions, similar to those formed by $\alpha$ Syn (Tenreiro et al., 2016). $\beta$ Syn can induce cell death by mechanisms associated with vesicular trafficking impairment or oxidative stress, similarly as it is described for $\alpha$ Syn toxicity. Co-expression of $\alpha$ Syn and $\beta$ Syn enhanced the cytotoxicity due to increased dosage of toxic species in an additive manner. Both different synucleins were able to form heterodimers in yeast as well as in human cells. These findings emphasize pathogenesis-related cellular role of $\beta$ Syn, suggesting that increased levels of $\beta$ Syn enhance $\alpha$ Syn-induced cytotoxicity due to dosage effects. The molecular mechanisms that control $\beta$ Syn turnover in the cell are yet elusive.

In contrast to $\alpha$ Syn, PTM of $\beta$ Syn are hardly studied. $\beta$ Syn has been found to be phosphorylated at S118 in vitro and in vivo (Nakajo et al., 1993; Mbefo et al., 2010), however other PTMs were not yet reported. Since $\alpha$ Syn and $\beta$ Syn proteins are highly similar, there have to be differences in their molecular behavior that might explain their differential contribution to neurodegeneration. 
We used yeast as a reference cell to exploit the molecular mechanisms that affect $\beta$ Syn turnover in the cell. We showed that SUMO is an important modulator of protein stability. $\beta$ Syn is sumoylated in yeast at three lysine residues and sumoylation supports aggregate formation. The exchange of the codons for the sumoylation sites decreased $\beta$ Syn aggregate formation but did not change cellular cytotoxicity monitored as yeast growth. However, downregulation of the entire cellular sumoylation pool drastically enhanced $\beta$ Syn-induced cytotoxicity. We demonstrate in yeast cells that intact sumoylation machinery is prerequisite for the degradation of soluble as well as aggregated $\beta$ Syn protein. $\beta$ Syn is degraded mainly by the $26 \mathrm{~S}$ proteasome, in contrast to $\alpha$ Syn that is degraded predominantly by the autophagy/vacuolar pathway. These findings reveal distinct molecular mechanisms of protein turnover for $\beta$ Syn in comparison to $\alpha$ Syn.

\section{MATERIALS AND METHODS}

\section{Plasmid Construction, Yeast Strains, Transformation and Growth Conditions}

Plasmids and Saccharomyces cerevisiae strains are listed in Tables 1, 2. Yeast plasmids expressing SNCB-GFP fusion were cloned into the SmaI site of the integrative plasmids pRS304 or pRS306 using GENEART Seamless cloning and assembly kit (Life technologies). The $\beta$ Syn mutant constructs were generated by site-directed mutagenesis of the corresponding plasmids. All constructs were verified by DNA sequencing.

The GAL1-SNCB-GFP was integrated into the mutated ura3-1 locus of S. cerevisiae W303-1A strain using an intact URA3 gene on the corresponding integrative plasmid for selection. The number of the integrated copies was determined by Southern hybridization as described previously (Petroi et al., 2012). The GAL1::SNCB or its derivatives were integrated into the $\operatorname{trp} 1-1$ locus.

S. cerevisiae strains W303-1A, smt $3^{\text {ts }}$ and $u l p 1^{\text {ts }}$ were used for transformations performed by standard lithium acetate
TABLE 1 | Plasmids used in this study.

\begin{tabular}{|c|c|c|}
\hline Name & Description & Source \\
\hline p426 & URA3, $2 \mu \mathrm{m}$, pUC origin, AmpR & Mumberg et al. (1994) \\
\hline pRS304 & TRP1, pUC origin, AmpR & Sikorski and Hieter (1989) \\
\hline pRS306 & URA3, pUC origin, AmpR & Sikorski and Hieter (1989) \\
\hline pME3759 & $\mathrm{p} 426-G A L 1-G F P$ & Petroi et al. (2012) \\
\hline pME3763 & p426-GAL 1::SNCA::GFP & Petroi et al. (2012) \\
\hline pME4102 & p426-GAL1::SNCB::GFP & Tenreiro et al. (2016) \\
\hline pME4103 & p426-GAL1::SNCG::GFP & Tenreiro et al. (2016) \\
\hline pME4624 & p426-GAL1::SNCB ${ }^{K 12 R}:: G F P$ & This study \\
\hline pME4625 & p426-GAL1::SNCB ${ }^{K 85 R}:: G F P$ & This study \\
\hline pME4626 & p426-GAL1::SNCB ${ }^{K 94 R}:: G F P$ & This study \\
\hline pME4627 & p426-GAL1::SNCB ${ }^{K 85 R ~ K 94 R:: G F P ~}$ & This study \\
\hline pME4628 & p426-GAL1::SNCB ${ }^{K 12}$ K85R K94R::GFP & This study \\
\hline pME4629 & pRS304-GAL1::SNCB & This study \\
\hline pME4630 & pRS304-GAL1::SNCB ${ }^{K 12 R}$ & This study \\
\hline pME4631 & pRS304-GAL1::SNCB ${ }^{K 85 R}$ & This study \\
\hline pME4632 & pRS304-GAL1::SNCB ${ }^{K 94 R}$ & This study \\
\hline pME4633 & pRS304-GAL1::SNCB K85R K94R & This study \\
\hline pME4634 & pRS304-GAL1::SNCB ${ }^{\text {K12R K85R K94R }}$ & This study \\
\hline pME4635 & pRS306-GAL1::SNCB::GFP & This study \\
\hline
\end{tabular}

protocol (Gietz et al., 1992). All strains were grown in Synthetic complete medium (SC; Guthrie and Fink, 1991) lacking the nutrient amino acid corresponding to the marker, and supplemented with $2 \%$ raffinose or $2 \%$ glucose. $\alpha$ Syn or $\beta$ Syn expression was induced by shifting yeast cells cultivated overnight in raffinose to $2 \%$ galactose-containing medium $\left(\mathrm{OD}_{600}=0.1\right)$.

\section{Spotting Assay}

For growth test on solid medium, yeast cells were pre-grown in minimal medium containing $2 \%$ raffinose lacking the corresponding marker to mid-log phase. Cells were normalized to equal densities, serially diluted 10 -fold starting with an $\mathrm{OD}_{600}$ of 0.1 , and spotted on SC-plates containing either $2 \%$ glucose or $2 \%$ galactose and lacking in corresponding marker. $s m+3^{t s}$ mutant cells were incubated at permissive temperature $\left(25^{\circ} \mathrm{C}\right)$ and restrictive temperature $\left(30^{\circ} \mathrm{C}\right)$. After 3 days incubation the plates were photographed.

TABLE 2 | Yeast strains used in this study.

\begin{tabular}{|c|c|c|}
\hline Name & Genotype & Source \\
\hline W303-1A & MATa; ura3-1; trp1-1; leu2-3_112; his3-11; ade2-1; can1-100 & EUROSCARF \\
\hline RH3465 & W303 containing GAL1::GFP in ura3 locus & Petroi et al. (2012) \\
\hline $\mathrm{RH} 3468$ & W303 containing three genomic copies of GAL1::SNCAWT ::GFP in ura3 locus & Petroi et al. (2012) \\
\hline $\mathrm{RH} 3603$ & ulp1ts containing Ylplac211-ADH-His6-SMT3 in his3 locus & Shahpasandzadeh et al. (2014) \\
\hline$s m t 3^{t s}$ & S542: MAT $\alpha$, smt3-331 & Dieckhoff et al. (2004) \\
\hline $\mathrm{RH} 3700$ & W303 containing one genomic copy of GAL1::SNCB ${ }^{W T}:: G F P$ in ura3 locus & This study \\
\hline $\mathrm{RH} 3703$ & RH3603 containing GAL 1::SNCB ${ }^{W T}$ in trp1 locus & This study \\
\hline $\mathrm{RH} 3704$ & $\mathrm{RH} 3603$ containing GAL1::SNCB ${ }^{K 12 R}$ in trp1 locus & This study \\
\hline $\mathrm{RH} 3705$ & $\mathrm{RH} 3603$ containing GAL1::SNCB ${ }^{K 85 R}$ in trp1 locus & This study \\
\hline $\mathrm{RH} 3706$ & RH3603 containing GAL1::SNCB ${ }^{K 94 R}$ in trp1 locus & This study \\
\hline $\mathrm{RH} 3707$ & RH3603 containing GAL1::SNCB ${ }^{K 85 R ~ K 94 R}$ in trp1 locus & This study \\
\hline $\mathrm{RH} 3708$ & RH3603 containing GAL 1::SNCB ${ }^{K 12 R ~ K 85 R ~ K 94 R ~ i n ~ t r p 1 ~ l o c u s ~}$ & This study \\
\hline
\end{tabular}




\section{Growth Analysis in Liquid Culture}

For growth tests in liquid cultures, cells were pre-grown in $2 \%$ raffinose-containing selective SC medium until logarithmic growth phase and inoculated in $2 \%$ galactose-containing SC medium to equal densities of $\mathrm{OD}_{600}=0.1$. Optical density measurements of $150 \mu \mathrm{l}$ cell cultures were performed in quadruplicates in 96-well plates for $24 \mathrm{~h}$ using a microplate reader with temperature control and continuous shaking (Infinite M200, Tecan).

\section{Fluorescence Microscopy and Quantifications}

Wild type (W303-1A) yeast cells harboring $\beta$ Syn were grown in SC selective medium containing $2 \%$ raffinose at $30^{\circ} \mathrm{C}$ and $s m t 3^{t s}$ mutant cells at $25^{\circ} \mathrm{C}$ overnight, and transferred to $2 \%$ galactose containing medium for induction of $\beta$ Syn expression for $6 \mathrm{~h}$. smt $3^{\text {ts }}$ mutant cells were induced at $25^{\circ} \mathrm{C}$ or $30^{\circ} \mathrm{C}$. Fluorescent images were obtained with Zeiss Observer. Z1 microscope (Zeiss) equipped with a CSU-X1 A1 confocal scanner unit (YOKOGAWA), QuantEM:512SC digital camera (Photometrics) and SlideBook 6.0 software package (Intelligent Imaging Innovations). For quantification of aggregation at least 200 cells were counted per strain and per experiment. The number of cells presenting inclusions was referred to the total number of cells counted. The values are mean of at least three independent experiments.

\section{Immunoblotting}

Wild type (W303-1A) yeast cells harboring $\beta$ Syn were pre-grown at $30^{\circ} \mathrm{C}$ in SC selective medium containing $2 \%$ raffinose. Cells were transferred to SC medium containing $2 \%$ galactose at $\mathrm{OD}_{600}=0.1$ to induce the GAL1 promoter for $6 \mathrm{~h}$. $s m t 3^{\text {ts }}$ or ulp $1^{\text {ts }}$ cells harboring $\beta$ Syn were pre-incubated at $25^{\circ} \mathrm{C}$ and later transferred to either $25^{\circ} \mathrm{C}$ or $30^{\circ} \mathrm{C}$. Total protein extracts were prepared and the protein concentrations were determined with a Bradford assay. Forty microgram of each protein were subjected to $12 \%$ SDS-polyacrylamide gel electrophoresis and transferred to a nitrocellulose membrane. Membranes were probed with $\beta$ Syn rabbit monoclonal antibody (abcam, UK), GFP rat monoclonal antibody (Chromotek, Germany), SUMO rabbit polyclonal antibody (Rockland Immunochemicals Inc., USA) or ubiquitin mouse monoclonal antibody for detection of poly-ubiquitinated and ubiquitinated proteins (clone P4D1A11, Millipore). GAPDH mouse monoclonal antibody (Thermo Fisher Scientific, USA) was used as loading controls. Pixel density values for Western quantification were obtained from TIFF files generated from digitized X-ray films (KODAK) and analyzed with the ImageJ software (NIH, Bethesda, MD, USA). Before comparison, sample density values were normalized to the corresponding loading control.

\section{Ultracentrifugation and Fractionation}

The sedimentation assay, extraction of SDS-soluble and insoluble $\beta$ Syn protein fractions were performed as described (Alberti et al., 2010) with modifications. Equal number of yeast cells corresponding to total $\mathrm{OD}=10$ were collected by centrifugation and resuspended in lysis buffer (50 mM Tris- $\mathrm{HCl} \mathrm{pH} \mathrm{7.5,} 1 \mathrm{mM}$ EDTA, $5 \mathrm{mM}$ DTT, $1 \times$ protease inhibitor mix (Roche). The cells were lysed by shaking with glass beads at $4^{\circ} \mathrm{C}$. The crude lysate was centrifuged for $5 \mathrm{~min}$ at $500 \mathrm{~g}$ to pellet the cell debris. Two-hundred microliter of each cleared lysate was centrifuged at $100,000 \mathrm{~g}$ for $30 \mathrm{~min}$. The supernatant was designated as soluble protein. The pellet was washed three times with the lysis buffer, resuspended in $200 \mu 1$ lysis buffer containing $2 \%$ SDS and incubated on ice for $30 \mathrm{~min}$. The suspension was centrifuged for $30 \mathrm{~min}$ at $100,000 \mathrm{~g}$ and the supernatant was labeled as SDS-soluble protein fraction. The pellet was washed three times with lysis buffer, resuspended in $200 \mu \mathrm{l} 6 \mathrm{M}$ urea and designated as SDS-insoluble fraction. Equal amount from each fraction $(20 \mu \mathrm{l})$ was analyzed by SDS-PAGE and Western blotting.

\section{Flow Cytometry}

Cells were grown as above and protein expression was induced as described for $6 \mathrm{~h}$. Before measuring, cells were re-suspended in $50 \mathrm{mM}$ trisodium citrate buffer, $\mathrm{pH}$ 7.0. Flow cytometry analysis was performed on a BD FACSCANTO II (Becton Dickinson). Fifty thousand events were counted for each experiment. Data analysis was performed using the BD FACSDIVA software (Becton Dickinson). Representative examples that are shown in the Figures were repeated at least three times. Yeast cell membrane integrity was analyzed with PI staining. Yeast cells were incubated with $12.5 \mu \mathrm{g} / \mathrm{ml}$ PI for $30 \mathrm{~min}$. As a positive control, cells were boiled for $10 \mathrm{~min}$ at $95^{\circ} \mathrm{C}$.

\section{Promoter Shut-Off Assay and Chemical Treatments}

Yeast cells carrying $\beta$ Syn were pre-grown in selective SC medium containing $2 \%$ raffinose overnight and shifted to $2 \%$ galactose-containing selective SC medium to induce the $\beta$ Syn expression for $4 \mathrm{~h}$. Afterwards, cells were shifted to SC medium supplemented with $2 \%$ glucose to shut-off the promoter. For experiments with temperature sensitive yeast strain $s m t 3^{\text {ts }}$, pre-incubation was performed at $25^{\circ} \mathrm{C}$. Induction of $\beta$ Syn expression and the promoter shut-off assay were performed at $25^{\circ} \mathrm{C}$ and $30^{\circ} \mathrm{C}$. Five hours after promoter shut-off, cells were visualized by fluorescence microscopy. The reduction of number of cells displaying $\beta$ Syn inclusions was recorded. To study the lysosome/vacuole degradation pathway (autophagy) phenylmethanesulfonyl fluoride (PMSF) in ethanol (EtOH) was applied to the suspension in a final concentration of $1 \mathrm{mM}$. For impairment of the proteasomal degradation system Carbobenzoxyl-leucinylleucinyl-leucinal (MG132) dissolved in dimethyl sulfoxide (DMSO) was added to the cell suspension in a final concentration of $75 \mu \mathrm{M}$. Drug treatment was conducted concomitantly with the shift to glucose-supplemented medium. In parallel, equal volume of DMSO or EtOH was applied to the control cells. For drug treatment with MG132 induction-medium containing galactose and shut-off-medium containing glucose was supplemented with $0.003 \%$ SDS and $0.1 \%$ proline.

\section{$\mathrm{Ni}^{2+}$-NTA Affinity Chromatography}

ulp1 $1^{\text {ts }}$ mutant cells carrying GAL1-SNCB integrations and His6-tagged Smt3 (His6-SMT3) were pre-grown in $200 \mathrm{ml} \mathrm{SC}$ 
medium containing $2 \%$ raffinose at $30^{\circ} \mathrm{C}$ overnight. Total cells harvested by centrifugation were transferred to 21 YEPD liquid medium containing $2 \%$ galactose for $12 \mathrm{~h}$ induction. Cells were collected and lysed by $25 \mathrm{ml} 1.85 \mathrm{M} \mathrm{NaOH}$ containing $7.5 \%$ ß-mercaptoethanol for $10 \mathrm{~min}$ on ice. Proteins were precipitated

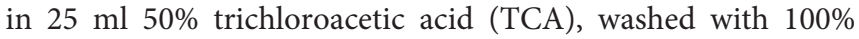
cold acetone, and suspended in $25 \mathrm{ml}$ buffer A (6 M guanidine $\mathrm{HCl}, 100 \mathrm{mM}$ sodium phosphate, $10 \mathrm{mM}$ Tris/ $\mathrm{HCl}, \mathrm{pH} 8.0$ ) and rotated for $1 \mathrm{~h}$ at $25^{\circ} \mathrm{C}$. The supernatant was cleared by centrifugation; the $\mathrm{pH}$ was adjusted to 7.0 by $1 \mathrm{M}$ Tris base and supplemented with imidazole to final concentration of $20 \mathrm{mM}$. After equilibration of the His GraviTrap column (GE Healthcare Life Science, Buckinghamshire, United Kingdom) with $5 \mathrm{ml}$ of buffer A containing $20 \mathrm{mM}$ imidazole, proteins were applied to the column and the flow-through fraction was collected for analysis. The column was washed with buffer A supplemented with $20 \mathrm{mM}$ imidazole and then with buffer B (8 M Urea, $100 \mathrm{mM}$ sodium phosphate, $10 \mathrm{mM}$ Tris, $\mathrm{pH}$ 6.3). Then the column was washed with buffer C (50 mM Tris pH 8.0, $300 \mathrm{mM} \mathrm{NaCl}, 20 \mathrm{mM}$ imidazole). Finally, the proteins were eluted four times with $1 \mathrm{ml}$ of $200 \mathrm{mM}$ imidazole resolved in buffer C. Protein concentration in the eluted fractions was determined with Bradford assay.

\section{Statistical Analysis}

Data were analyzed using GraphPad Prism 5 (San Diego, CA, USA) Software and were presented as mean \pm SEM of at least three independent experiments. The significance of differences was calculated using Students $t$-test and One-way Anova test. $P$ value $<0.05$ was considered to indicate a significant difference.

\section{RESULTS}

\section{$\beta$ Syn Has a Higher Toxicity Threshold Than $\alpha$ Syn When Expressed in Yeast}

We evaluated the impact of $\alpha$ Syn, $\beta$ Syn and $\gamma$ Syn GFP-tagged proteins on growth of Saccharomyces cerevisiae cells. The expression was controlled by the GAL1 promoter, which can be repressed in the presence of glucose and induced in the presence of galactose. High level expression from $2 \mu$ plasmid of $\alpha$ Syn resulted in the described growth impairment (Outeiro and Lindquist, 2003; Petroi et al., 2012). Cells expressing $\beta$ Syn were also inhibited in growth, whereas expression of $\gamma$ Syn resulted in wild type yeast growth similar of GFP control (Tenreiro et al., 2016; Figure 1A). Fluorescent microscopy was used to assess, whether the synuclein-induced growth inhibition is accompanied with aggregate formation. $\alpha$ Syn and $\beta$ Syn expression resulted in formation of similar cytoplasmic inclusions (Figure 1B). Quantification of the cells displaying inclusions revealed similar percentages of $\alpha$ Syn and $\beta$ Syn expressing cells with inclusions $6 \mathrm{~h}$ after induction of protein expression, whereas $\gamma \mathrm{Syn}$ expressing cells did not exhibit formation of aggregates (Figure 1C).

Previous studies revealed that a threshold level for $\alpha$ Syninduced toxicity was reached if expression was driven by three genomic copies of the $\alpha$ Syn encoding gene (Petroi et al., 2012). We aimed to characterize the threshold for $\beta$ Syn-induced toxicity. Strains were constructed with single, double or triple integrations of $\beta$ Syn-encoding genes at the single ura 3 locus. Growth assays revealed no growth inhibition by expression of $\beta$ Syn from single, double or triple genomic copies. In contrast cells expressing $\alpha$ Syn from three copies were impaired in growth (Figure 1D). This growth phenotype correlated with increased aggregate formation. Expression from one copy of $\beta$ Syn did not result in aggregate formation. Two copies of $\alpha$ Syn and $\beta$ Syn had lower percentages of cells with aggregates, whereas expression from three copies of $\alpha$ Syn gene resulted in $91 \%$ of cells displaying aggregates in comparison with $24 \%$ of cells expressing $\beta$ Syn (Figure 1E). The measured differences in toxicity were not due to different protein levels of the two variants, as observed with Western hybridization after $6 \mathrm{~h}$ induction of expression (Figures 1F,G).

The solubility of $\beta$ Syn in strains differing in the potential for aggregate formation was analyzed. Cells, expressing $\beta$ Syn from two or three genomic copies and cells, overexpressing $\beta$ Syn from $2 \mu$ plasmid were used. Crude protein extracts were prepared from equal number of cells $6 \mathrm{~h}$ after induction of protein expression. The protein extracts were subjected to fractionation to produce soluble, SDS-soluble and SDS-insoluble fractions (Figures $\mathbf{1 H}, \mathbf{I}$ ). Comparison of the different $\beta$ Syn fractions revealed significant increase towards SDS-insoluble fraction in cells, displaying higher aggregate formation. The results illustrate a direct correlation between $\beta$ Syn aggregation and the accumulation of insoluble protein species, suggesting that the observed fluorescent foci are indicative for $\beta$ Syn aggregate formation.

These results demonstrate that expression from three copies of $\beta$ Syn encoding gene is below the toxicity threshold. $\beta$ Syn is less toxic with a higher threshold for cytotoxicity and aggregate formation than $\alpha$ Syn.

\section{BSyn Is Sumoylated in Yeast at Three Lysine Residues Within SUMO Consensus Motifs}

$\alpha$ Syn was shown to be efficiently sumoylated in human cells lines and the major sumoylation sites are conserved from yeast to human (Krumova et al., 2011; Shahpasandzadeh et al., 2014). We examined, whether $\beta$ Syn is sumoylated in yeast cells. In silico analysis with SUMOplot analysis predicted three putative SUMO consensus motifs at lysine residues 12,85 or 94 (K12, K85, K94; Table 3). A temperature-sensitive strain deficient for the gene, encoding the SUMO-deconjugation isopeptidase $\left(u l p 1^{t s}\right)$ that expressed $\mathrm{His}_{6}$-tagged yeast SUMO protein Smt3 (Petroi et al., 2012) was used for enrichment of SUMO-conjugates (Figure 2A). $\beta$ Syn was expressed in the $u l p 1^{\text {ts }}-S M T 3-H i s 6$ strain and SUMO-conjugates were enriched by $\mathrm{Ni}^{2+}$-NTA affinity chromatography under denaturing conditions. Immunoblotting analysis with $\beta$ Syn antibody revealed SUMO-modified $\beta$ Syn protein with an apparent molecular mass of $\sim 35 \mathrm{kDa}$ (Figure $2 \mathrm{~B}$ ) that could be separated from the non-modified $15 \mathrm{kDa} \beta S y n$ protein.

In order to map the sumoylation sites of $\beta$ Syn, mutants with single (K12R; K85R; K94R), double (K85/K94R) and triple 
A

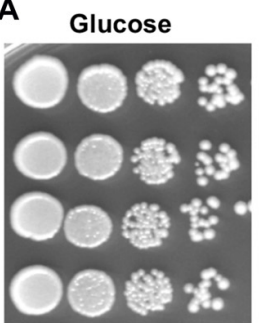

Galactose

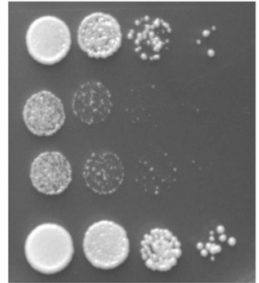

GFP

aSyn-GFP

BSyn-GFP

YSyn-GFP

B GFP

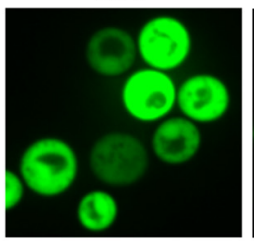

aSyn-GFP

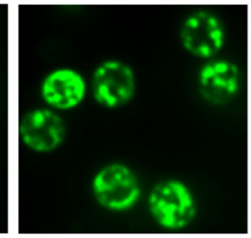

BSyn-GFP

YSyn-GFP
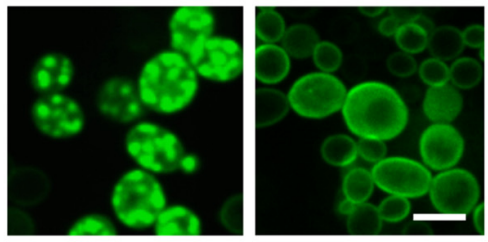

C

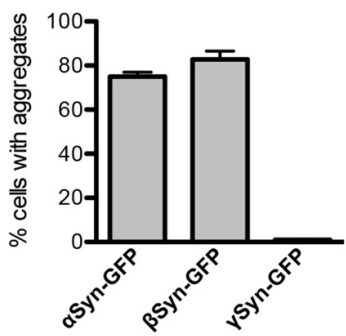

D

Glucose

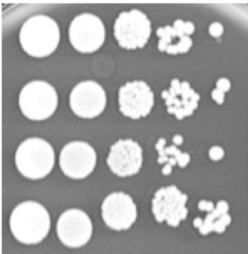

$008 \%$
$00 \div$.
Galactose

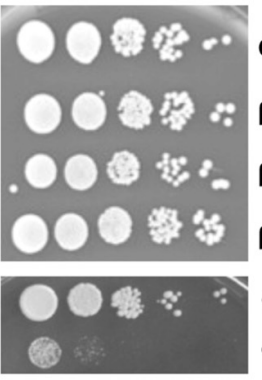

GFP

GFP
E
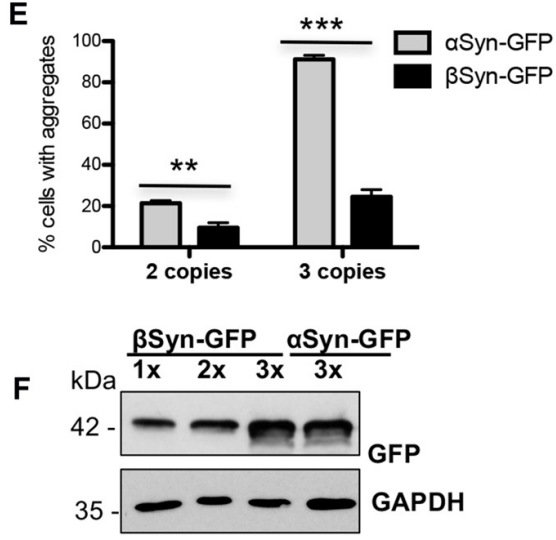

G

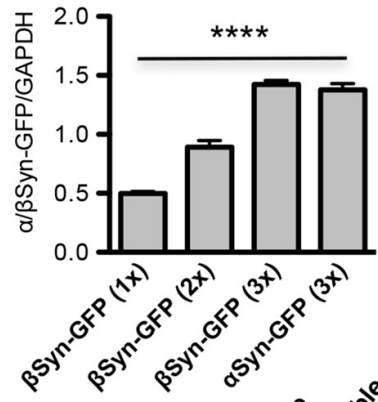

H

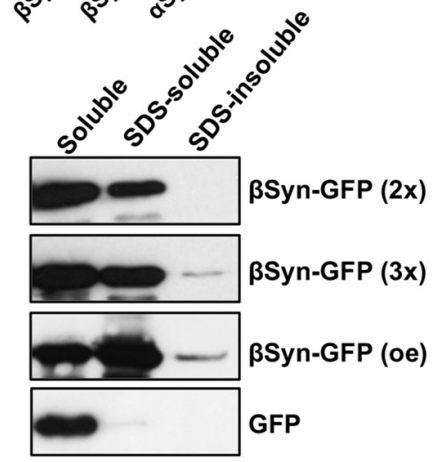

ßSyn-GFP (1x)

ßSyn-GFP (2x)

$\beta S y n-G F P(3 x)$

aSyn-GFP (3x)
I

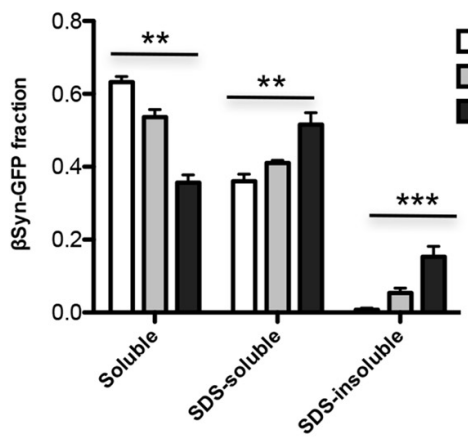

FIGURE 1 | $\beta$-synuclein ( $\beta$ Syn)-GFP expression impairs yeast growth. (A) Wild type yeast cells (W303) were transformed with a high copy plasmid carrying $\alpha$-synuclein ( $\alpha$ Syn)-GFP, $\beta$ Syn-GFP and $\gamma$-synuclein ( $\gamma$ Syn)-GFP under the control of GAL1. GFP expressing cells, expressed from the same promoter, served as control. Yeast cells were spotted in 10-fold dilutions on selection plates containing glucose (GAL1 promoter "OFF") or galactose (GAL1 promoter "ON"). (B) Live-cell fluorescence microscopy of yeast cells expressing GAL1-driven synuclein isoforms from $2 \mu$ plasmids. Yeast cells, pre-grown to mid-log phase, were induced in galactose-containing medium and examined for aggregates at $6 \mathrm{~h}$ of induction. Scale bar $-5 \mu \mathrm{M}$. (C) Aggregate quantification of yeast cells, expressing synuclein-GFP isoforms. For each strain, the number of cells displaying cytoplasmic foci is presented as percent of the total number of cells. For quantification of 


\section{FIGURE 1 | Continued}

aggregation at least 200 cells were counted per strain and per experiment. The results are mean from at least five independent experiments \pm SD. (D) Spotting assay of yeast cells expressing one (1x), two (2x) or three (3x) copies of $\beta$ Syn and three copies of $\alpha$ Syn. Yeast cells, expressing GFP were used as a control. The yeast cells were spotted in 10-fold dilutions on selective SC-Ura plates containing $2 \%$ glucose and $2 \%$ galactose.

(E) Aggregate quantification of yeast cells, expressing two or three copies of genes, encoding $\alpha$ Syn-GFP and $\beta$ Syn-GFP at $6 \mathrm{~h}$ of induction. Expression of $\beta S y n-G F P$ from a single copy gene did not result in aggregate formation.

Significance of differences was calculated with $t$-test ${ }^{* *} p<0.01$;

$\left.{ }^{* * *} p<0.001 ; n=3\right)$. (F) Western blot analysis of crude protein extracts of

GFP-tagged proteins, expressed from one, two or three copies of $\beta$ Syn and three copies of $\alpha$ Syn encoding genes, respectively. GAPDH was used as a loading control. (G) Densitometric analysis of the immunodetection of $\beta S y n-G F P$ relative to the GAPDH loading control. Significance of differences was calculated with One-way Anova test $(* * * * 0.0001 ; n=3)$.

(H) Distribution of $\beta$ Syn-GFP levels across different solubility fractions. Yeast cells, expressing $\beta$ Syn-GFP from two (2x) or three (3x) genomic copies or overexpressing (oe) the protein from high copy plasmid were induced for $6 \mathrm{~h}$ in galactose medium. Starting from equal number of cells, crude protein extracts were prepared and fractionated by ultracentrifugation to produce soluble, SDS-soluble and SDS-insoluble fractions. Fractionation of GFP was performed as a control. Equal amounts from all fractions were analyzed by immunoblotting with $\beta$ Syn or GFP antibody. (I) Densitometric analysis of the immunodetection of $\beta$ Syn-GFP. The relative ratio of each $\beta$ Syn fraction is normalized to the sum of the three fractions. Significance of differences was calculated with One-way Anova test $\left.{ }^{* *} p<0.01 ;{ }^{* * *} p<0.001 ; n=4\right)$.

TABLE 3 | $\beta$-synuclein ( $\beta$ Syn) putative sumoylation sites.

\begin{tabular}{llc}
\hline Position & Group & Score \\
\hline K86 & AATGL VKRE EFPTD & 0.93 \\
K95 & EFPTD LK PEE EVAQE & 0.91 \\
K12 & KGLSM AKEG WAAA & 0.62
\end{tabular}

The score represents the probability for the SUMO consensus sequence (bold) to be involved in SUMO conjugation. The lysine acceptor site is underlined.

(K12/K85/K94R) lysine substitutions of the three putative $\beta$ Syn sumoylation sites were generated. The $\beta$ Syn lysine mutants were expressed in ulp ${ }^{\text {ts }}$-SMT3-His6 strain and SUMO-conjugates were purified by $\mathrm{Ni}^{2+}$-NTA pull-down as above. Single substitutions of each codon for putative sumoylation site, as well as double substitutions (K85/K94R) did not result in loss of the $35 \mathrm{kDa}$ band. Only when all three putative SUMO-acceptor sites were mutated simultaneously (K12/K85/K94R), complete abolishment of sumoylation was observed (Figure 2C). These results support that $\beta$ Syn sumoylation in vivo comprises all three $\mathrm{K} 12, \mathrm{~K} 85$ and K94 lysine residues, which are embedded in a SUMO consensus motif.

\section{Loss of Sumoylation of $\beta$ Syn Reduces Inclusion Formation Without Reducing Cytotoxicity}

We examined whether modification of $\beta$ Syn as a direct SUMO target affects $\beta$ Syn-induced growth inhibition in yeast. Wild type $\beta$ Syn, the single lysine mutants (K12R; K85R; K94R), as well as the triple lysine mutant $(\mathrm{K} 12 / \mathrm{K} 85 / \mathrm{K} 94 \mathrm{R})$ were expressed in yeast. The effect of abolishing the sumoylation acceptor sites of $\beta$ Syn on yeast growth was examined with spotting test (Figure 3A). Yeast cells were inhibited in growth and no significant differences were observed, when single SUMO acceptor sites or all three SUMO acceptor sites were substituted. Growth in liquid medium resulted in similar effects (Figures 3B,C). Cells, expressing $\beta$ Syn or sumoylation deficient mutants revealed reduced growth in comparison to the GFP control, however no significant differences in growth were observed among the $\beta$ Syn variants. Immunoblotting analysis revealed that all proteins were expressed at similar levels after $6 \mathrm{~h}$ induction of expression (Figures 3D,E). Fluorescent microscopy studies were performed to assess the aggregate formation of different $\beta$ Syn variants. Quantification of the number of cells with inclusions revealed a significant reduction in cells displaying $\mathrm{K} 12 \mathrm{R}$, as well as K12/K85/K94R mutants (Figures 3F,G). In order to assess, whether the differences in aggregate formation correlate with changes in cytotoxicity, propidium iodide (PI) staining for membrane permeability was performed as a sensitive method for quantification of yeast viability. Flow cytometry measurements of cells, expressing $\beta$ Syn and K12/K85/K94R, showed a significantly increased number of PI-positive cells in comparison to the GFP control (Figures 3H,I). No significant differences between cells expressing $\beta$ Syn and the triple lysine mutant were observed. These data correlate with the results from the growth assays and reveal that SUMO modifications of $\beta$ Syn enhances aggregate formation of the protein without significantly affecting cell growth and viability. This suggests that $\beta$ Syn aggregate formation and cytotoxicity are part of different molecular mechanisms.

\section{Sumoylation Protects Against $\beta$ Syn-Induced Toxicity}

The finding that SUMO modification at $\beta$ Syn acceptor sites did not change cytotoxicity suggested that sumoylation of additional target proteins or cellular pathways might be involved in cytoprotection against $\beta$ Syn-induced toxicity. We assessed the effect of sumoylation on $\beta$ Syn-induced toxicity using a yeast strain with a temperature sensitive SUMO-encoding gene $\left(s m t 3^{t s}\right)$. Growth of yeast $s m t 3^{t s}$ cells at restrictive temperature $\left(30^{\circ} \mathrm{C}\right)$ results in accumulation of non-functional SUMO-conjugates (Dieckhoff et al., 2004; Shahpasandzadeh et al., 2014). A growth assay was performed with cells, expressing $\beta$ Syn or K12/K85/K94R mutant from high copy plasmid at permissive temperature $\left(25^{\circ} \mathrm{C}\right)$ and restrictive temperature $\left(30^{\circ} \mathrm{C}\right.$; Figure $\left.4 \mathrm{~A}\right)$. Impairment of sumoylation at $30^{\circ} \mathrm{C}$ only slightly affected growth of the control strain expressing GFP, whereas expression of $\beta$ Syn or K12/K85/K94R mutants resulted in drastic growth inhibition under these conditions. Importantly, at permissive temperature cells that were not depleted of functional SUMO were less affected by expression of $\beta$ Syn and derivatives. Mutant $s m t 3^{t s}$ yeast strains with single integration of $\beta$ Syn or $3 \times \mathrm{xK} / \mathrm{R}$-encoding genes at the ura3 locus were constructed. Expression from single copy of $\beta$ Syn or K12/K85/K94R-encoding gene is lower than the toxicity threshold (Figure 1D). Accordingly, growth assays revealed no retardation at $25^{\circ} \mathrm{C}$ (Figure $4 \mathrm{~B}$ ). Inhibition of sumoylation at $30^{\circ} \mathrm{C}$ slightly affected growth of the strains expressing $\beta$ Syn or K12/K85/K94R. Quantitative growth assays in liquid cultures 

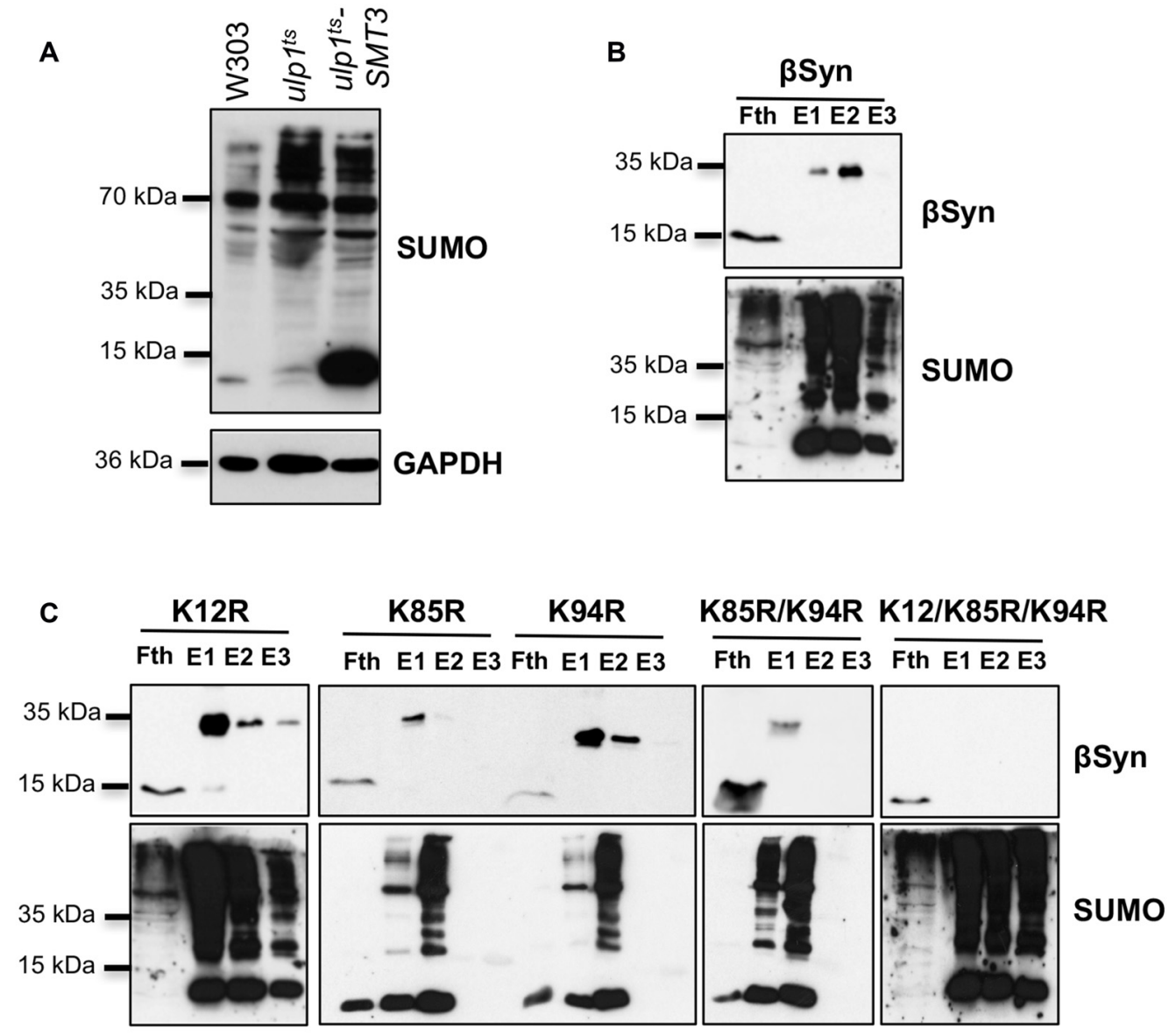

FIGURE 2 | $\beta$ Syn is sumoylated in yeast. (A) Enrichment of sumoylated conjugates in ulp $1^{\text {ts }}$ strain, expressing SMT3-HIS6. Western blot analysis of the total protein extract from the ulp $1^{\text {ts }}$ strain, deficient in SUMO-deconjugation, expressing His-tagged SMT3. ulp $1^{\text {ts }}$ and W303 were used as controls. SUMO-conjugated proteins were detected using specific SUMO antibody. GAPDH served as a loading control. (B) Ni ${ }^{2+}$ pull-down of ulp ${ }^{\text {ts }}$-SMT3-His6 strain expressing GAL1-driven $\beta$ Syn. Fth: flow-through; E1: Elution 1; E2: Elution 2; E3: Elution 3. The same membrane was stripped and probed with SUMO antibody verifying the Ni2+ pull-down. Modified $\beta$ Syn migrates at $\sim 35 \mathrm{kDa}$. Unmodified $\beta$ Syn migrates at $\sim 15 \mathrm{kDa}$. (C) $\mathrm{Ni}^{2+}$ pull-down of ulp $^{\text {ts }}$-SMT3-His6 strain expressing $\beta$ Syn sumoylation deficient mutants K12R, K85R, K94R, K85R/K94R and K12R/K85/K94R.

were performed with the $s m t 3^{t s}$ yeast cells, expressing $\beta$ Syn or K12/K85/K94R from single gene copy (Figures 4C,D). Analysis of the growth rate revealed significant differences in growth compared to the GFP control when sumoylation is impaired. These results indicated gain of $\beta$ Syn toxicity in strains expressing non-toxic levels of $\beta$ Syn or K12/K85/K94R under conditions of impaired sumoylation. This suggests a protective role of sumoylation for $\beta$ Syn-induced toxicity that is not dependent on direct modification of the protein.

Next, we examined whether increased sumoylation affects $\beta S y n$-induced cytotoxicity. We used the $u l p 1^{\text {ts }}$ strain, defective for SUMO de-conjugation, to enrich the pool of sumoylated proteins. Expression of $\beta$ Syn or K12/K85/K94R resulted in significantly reduced growth inhibition (Figure $4 \mathrm{E}$ ). This result revealed that up-regulation of sumoylation partially rescues the growth defect of yeast cells, expressing $\beta$ Syn.

We tested, whether there is a correlation between growth inhibition and aggregate formation of $\beta$ Syn and K12/K85/K94R variant. Aggregate formation was followed by life-cell microscopy and the number of cells with aggregates was counted (Figure 4F). Expression of $\beta S y n$ variants in $s m t 3^{t s}$ cells in presence or absence of functional SUMO did not result in changes of the percentage of cells with aggregates $6 \mathrm{~h}$ after induction (Figure 4G). However, expression of $\beta$ Syn and $\mathrm{K} 12 / \mathrm{K} 85 / \mathrm{K} 94 \mathrm{R}$ in $u l p 1^{\text {ts }}$ cells resulted in complete loss of aggregation after $6 \mathrm{~h}$ of induction and increased cytoplasmic staining (Figures 4F,H). Formation of aggregates was observed as late as $24 \mathrm{~h}$ after protein induction and there was a strong decrease of the percentage of cells with aggregates in comparison with $s m t 3^{t s}$ background (Figure 4G) or wild type W303 background (Figure 1C).

Our findings support a complex interplay between sumoylation, $\beta$ Syn-induced cytotoxicity and aggregate formation. Downregulation of functional cellular SUMO pools strongly inhibits yeast growth without affecting efficient aggregate formation. In contrast, higher levels of sumoylated 
A

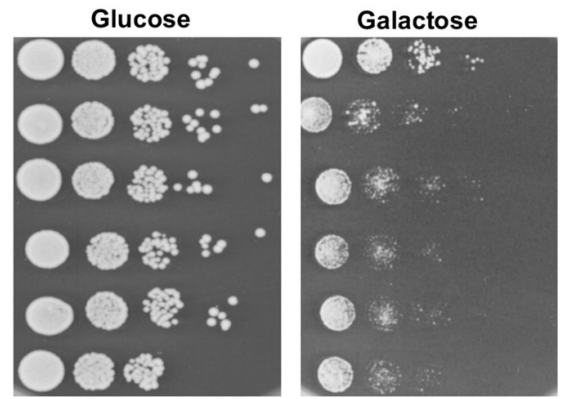

B

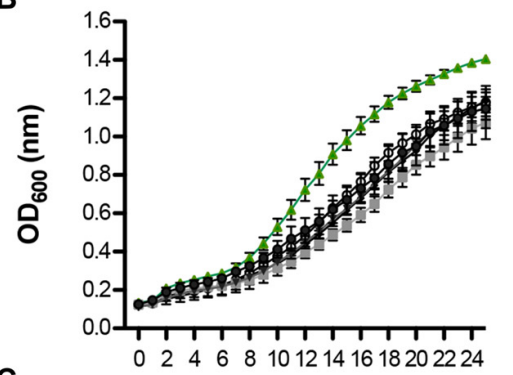

C

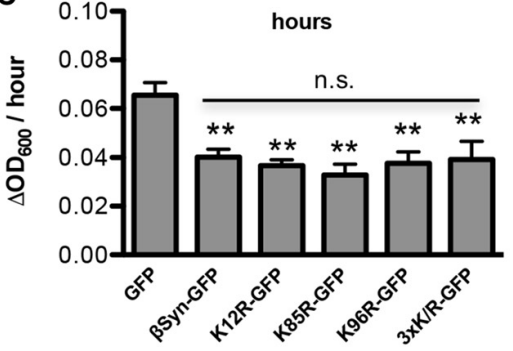

D

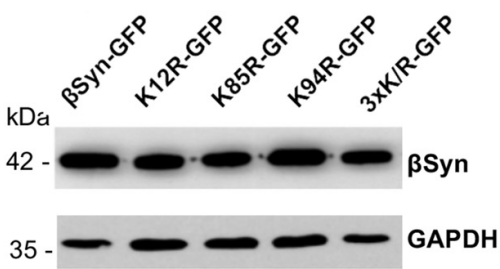

E

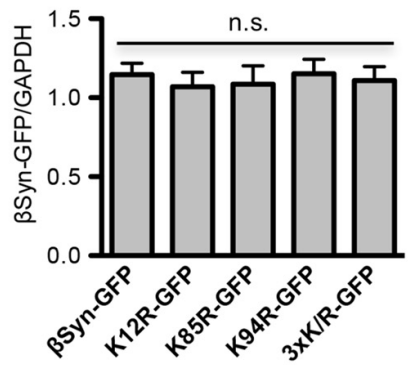

F

GFP

$\beta$ Syn-GFP

K12R-GFP

K85R-GFP

K94R-GFP

3xK/R-GFP

$\leadsto$ GFP

$\multimap$ BSyn-GFP

$\rightarrow$ K12R-GFP

- K85R-GFP

$\rightarrow$ K94R-GFP

$\rightarrow$ 3XK/R-GFP

G

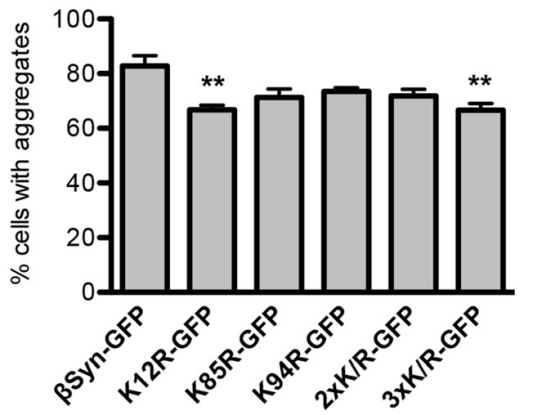

H
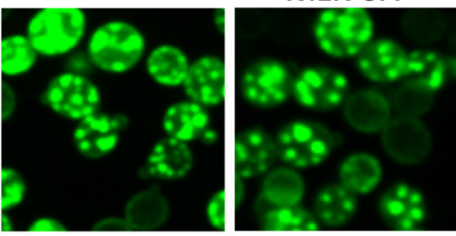

K85R-GFP

K94R-GFP

2xK/R-GFP
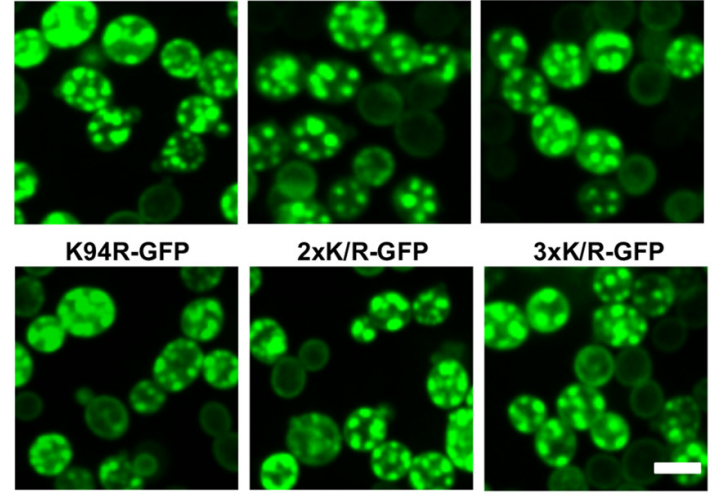

3xK/R-GFP
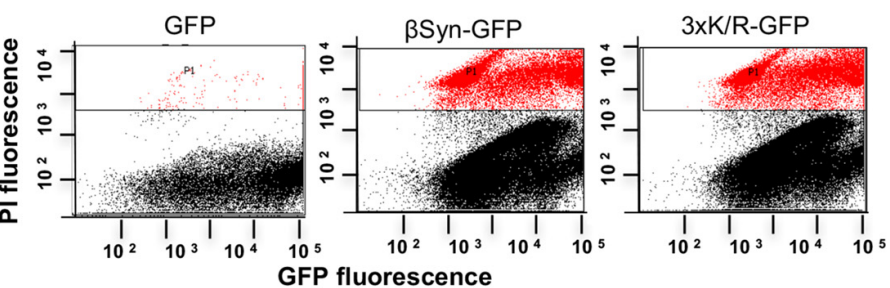

GFP fluorescence

I

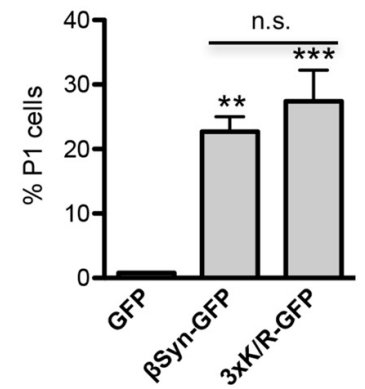

FIGURE 3 | High-copy expression of $\beta$ Syn-GFP variants in yeast. (A) Spotting assay of yeast cells expressing GAL 1-driven GFP-tagged $\beta$ Syn and $\beta$ Syn SUMOylation deficient mutants K12R, K85R, K94R, K85R/K94R (2xK/R) or K12R/K85R/K94R (3xK/R) from 2 $\mu$ plasmids. GFP expressing plasmid was used as a control. Yeast cells were spotted in 10-fold dilutions on selective plates containing 2\% glucose (GAL1 "OFF") or 2\% galactose (GAL1 "ON"). (B) Growth analysis of yeast cells from (A) in galactose-containing medium for $24 \mathrm{~h}$. (C) Growth rate of yeast cells from (B) in logarithmic phase. Significance of differences to the GFP control was calculated with $t$-test $(* * p<0.01 ; n=4)$. One-way Anova test revealed no significant differences among the $\beta$ Syn variants. (D) Western blot analysis of protein crude extracts from (A) after $6 \mathrm{~h}$ induction in galactose-containing medium. GAPDH served as a loading control. (E) Densitometric analysis of the immunodetection of 
FIGURE 3 | Continued

$\beta$ Syn-GFP relative to the GAPDH loading control. One-way Anova test revealed no significant differences among the $\beta$ Syn variants $(n=3)$.

(F) Live-cell fluorescence microscopy of yeast cells expressing GAL1-driven $\beta S y n-G F P$ variants from $2 \mu$ plasmids. Yeast cells, pre-grown to mid-log phase, were induced in galactose-containing medium and examined for aggregates at $6 \mathrm{~h}$ of induction. Scale bar $-5 \mu \mathrm{M}$. (G) Aggregate quantification of yeast cells, expressing $\beta$ Syn-GFP variants. For quantification of aggregation at least 200 cells were counted per strain and per experiment. The results are mean from at least four independent experiments \pm SD. Significance of differences was calculated with $t$-test $\left({ }^{* *} p<0.01\right.$ vs. $\beta$ Syn). (H) Propidium iodide (PI) fluorescence intensity of cells expressing $\beta$ Syn, 3xK/R and GFP (control) after $20 \mathrm{~h}$ induction of expression, assessed by flow cytometry analysis. (I) Quantification of Pl-positive yeast cells with higher fluorescent intensities (P1) than the background is presented. Significance of differences to the GFP control was calculated with $t$-test $\left(* * p<0.01 ;{ }^{* * *} p<0.001 ; n=4\right)$.

proteins by inhibition of SUMO de-conjugation enzymes prevented aggregate formation but still caused significant cellular growth inhibition. These effects are not dependent on direct sumoylation of $\beta$ Syn, since the growth and aggregation propensity of $\beta$ Syn and K12/K85/K94R-expressing cells is influenced similarly. The results suggest an indirect effect of SUMO on $\beta$ Syn-induced cytotoxicity by modification of other SUMO-target proteins that affect the aggregation or cytotoxicity of $\beta$ Syn.

\section{$\beta$ Syn Aggregates Are Cleared Mainly By the 26S Proteasome}

Both autophagy and UPS are implicated in degradation of $\alpha$ Syn and manifestation of PD. Inefficient protein clearance may lead to accumulation of toxic protein species and is sufficient to trigger neurotoxicity (Xilouri et al., 2013). In yeast, autophagy represents the major pathway for degradation of $\alpha$ Syn aggregates (Petroi et al., 2012; Tenreiro et al., 2014) and this process is promoted by sumoylation (Shahpasandzadeh et al., 2014).

We assessed the mechanism of $\beta$ Syn aggregate clearance mediated by the autophagy/vacuolar and the ubiquitinproteasome pathways. The impact of blocking these systems by drug treatments was studied. Expression of $\beta$ Syn and $\mathrm{K} 12 / \mathrm{K} 85 / \mathrm{K} 94 \mathrm{R}$ in $s m t 3^{t s}$ cells was induced for $4 \mathrm{~h}$ at permissive $\left(25^{\circ} \mathrm{C}\right.$; +SUMO) or restrictive temperature $\left(30^{\circ} \mathrm{C}\right.$; $\left.-\mathrm{SUMO}\right)$. Promoter shut-off was achieved by shifting the cells to glucosecontaining medium that represses the GAL1 promoter. PMSF was used as an inhibitor of autophagy/vacuolar pathway as described previously (Petroi et al., 2012; Kleinknecht et al., 2016; Figure 5A). Cells were imaged $5 \mathrm{~h}$ after promoter shut-off. Inhibition of autophagy resulted in increased number of cells with $\beta$ Syn or $\mathrm{K} 12 / \mathrm{K} 85 / \mathrm{K} 94 \mathrm{R}$ aggregates relative to the control. This suggests that the autophagy/vacuolar pathway contribute to $\beta$ Syn aggregate clearance. Inhibition of sumoylation resulted in similar aggregate clearance.

The contribution of the UPS to $\beta$ Syn degradation was analyzed by inhibiting this system with the proteasome inhibitor MG132 (Figure 5B). In the presence of functional SUMO, there was almost two-fold increase of cells with $\beta$ Syn aggregates in comparison to the control, when the proteasome is not inhibited. These data suggest a major contribution of the UPS to $\beta$ Syn or
K12/K85/K94R aggregate clearance. In contrast to autophagy, downregulation of sumoylation had a significant impact on the aggregate clearance by the proteasome, diminishing the contribution of this system on $\beta$ Syn aggregate clearance.

These results suggest that $\beta$ Syn aggregates in yeast are cleared mainly by the proteasome with a smaller contribution of autophagy/vacuolar pathway. The proteasomal clearance of $\beta$ Syn aggregates is not significantly affected by direct sumoylation of $\beta$ Syn lysine residues. Downregulation of sumoylation significantly reduces $\beta$ Syn aggregate clearance by the proteasome, however, does not affect the autophagy/vacuolar mediated aggregate clearance.

\section{Sumoylation Affects $\beta$ Syn Protein Turnover}

We next analyzed the effect of sumoylation on the protein stability of $\beta$ Syn and K12/K85/K94R by promoter shut-off experiments. The contribution of the autophagy/vacuole and the proteasome pathway was examined as described above by inhibiting each system with drug treatment. Protein expression was induced for $4 \mathrm{~h}$ in galactose medium, then the cells were shifted to glucose medium (GAL1-“OFF") and protein crude extracts were prepared $6 \mathrm{~h}$ after promoter shut-off. Assays were performed in W303 wild type, smt $3^{t s}$ and $u l p 1^{t s}$ strains at restrictive temperature $\left(30^{\circ} \mathrm{C}\right)$. Immunoblotting analysis was performed and steady-state levels of $\beta$ Syn variants were quantified (Figure 6). Inhibition of autophagy/vacuolar pathway by PMSF did not result in changes of $\beta$ Syn or K12/K85/K94R protein levels in wild type W303 background in comparison to the control (Figures 6A,B). Impairment of functional SUMO $\left(s m t 3^{t s}\right)$ did not significantly affect the protein levels of both $\beta$ Syn variants, when autophagy was inhibited. However, inhibition of the vacuolar/autophagy pathway resulted in significant increases of the protein levels of both $\beta$ Syn variants, when the pool of sumoylated proteins was up-regulated in $u l p 1^{\text {ts }}$ strain.

In contrast to autophagy, inhibition of the proteasome with MG132 in presence of functional SUMO in yeast wild type background had a strong impact on the protein stability (Figures 6C,D). Increased protein levels of both $\beta$ Syn variants were detected in comparison to the control, suggesting involvement of the UPS in degradation of $\beta$ Syn and $\mathrm{K} 12 / \mathrm{K} 85 / \mathrm{K} 94 \mathrm{R}$ proteins. Importantly, impairment of functional SUMO in $s m t 3^{t s}$ strain did not alter BSyn protein levels $6 \mathrm{~h}$ after promoter shut-off, when the proteasome was impaired, indicating that inhibition of sumoylation suppressed the proteasomal degradation of $\beta$ Syn and K12/K85/K94R derivative. Proteasome impairment resulted in significantly compromised degradation of the proteins in $u l p 1^{t s}$ strain, when the pool of sumoylated proteins is up-regulated, revealing the major impact of the proteasome and functional sumoylation machinery on $\beta$ Syn degradation.

These findings suggest that the 26S-proteasome represents the major pathway for degradation of $\beta$ Syn in the cells. Functional sumoylation machinery is required for the efficient degradation of the protein by the 26S-proteasome, indicating a cross-talk between sumoylation and UPS in $\beta$ Syn protein homeostasis. This process is not dependent on direct SUMO modification of $\beta$ Syn at K12, K85 or K94 acceptor sites. Sumoylation promotes 


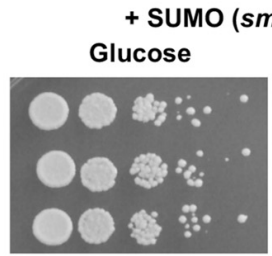

+ SUMO (smt $\left.3^{t s} 25^{\circ} \mathrm{C}\right)$

B
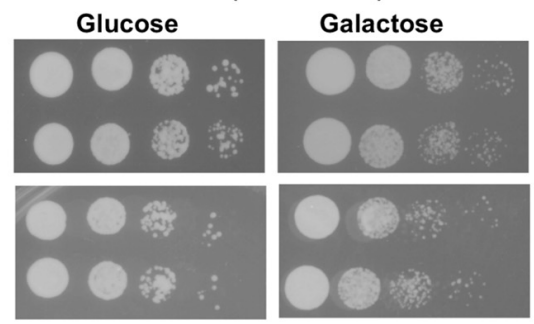

Galactose

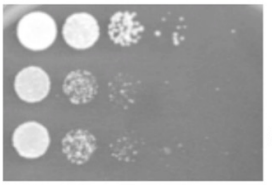

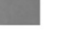

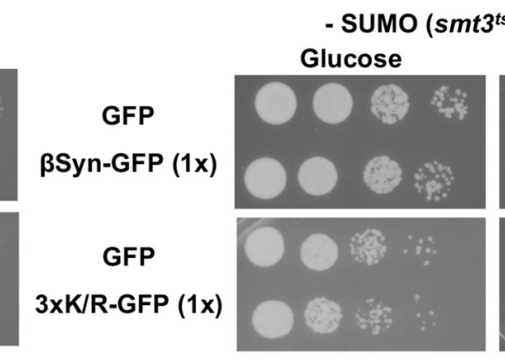

- SUMO (smt $\left.3^{\text {ts }} 30^{\circ} \mathrm{C}\right)$

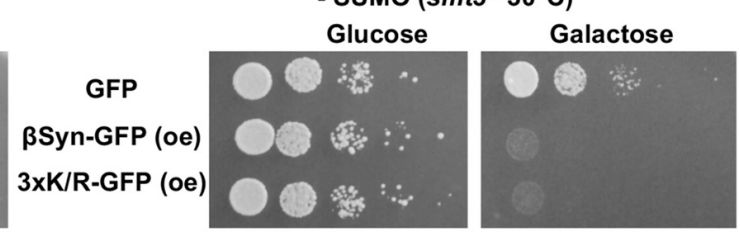

- SUMO (smt $\left.3^{\text {ts }} 30^{\circ} \mathrm{C}\right)$

Galactose

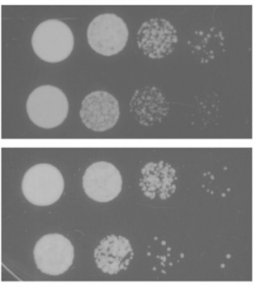

C

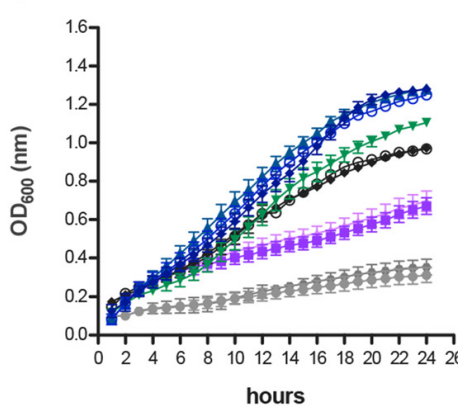

E

+ SUMO (ulp1ts $\left.30^{\circ} \mathrm{C}\right)$

Glucose

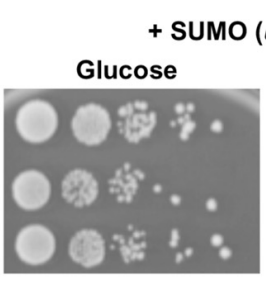

$\rightarrow$ GFP 25ㄷ

- $\beta$ Syn-GFP(1x) $25^{\circ} \mathrm{C}$

$\simeq 3 \times$ KK/R-GFP (1x) $25^{\circ} \mathrm{C}$

$\rightarrow$ GFP $30^{\circ} \mathrm{C}$

$\rightarrow$ BSyn-GFP (1x) $30^{\circ} \mathrm{C}$

$\rightarrow 3 \times K / R-G F P(1 \mathrm{x}) 30^{\circ} \mathrm{C}$

- BSyn-GFP (oe) 250C

- 3XK/R-GFP (oe) 250C

$\rightarrow \beta S y n-G F P(o e) 30^{\circ} \mathrm{C}$

$\rightarrow \quad 3 \times K / R-G F P(o e) 30^{\circ} \mathrm{C}$
D

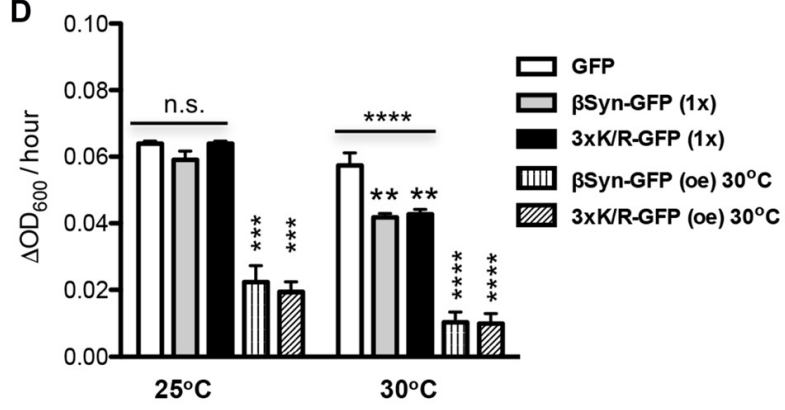

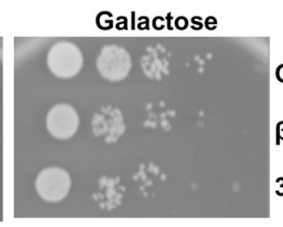

GFP

ßSyn-GFP (oe) 3xK/R-GFP (oe)

F
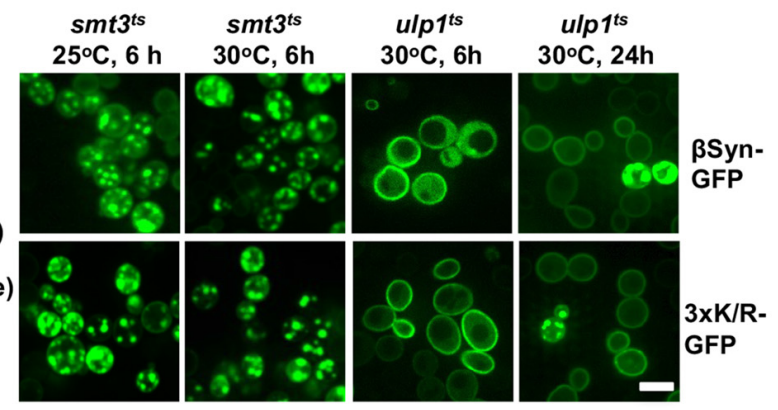

G
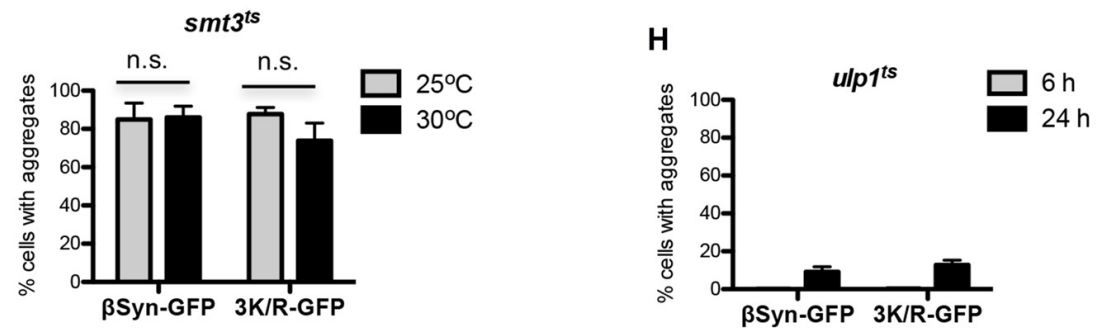

FIGURE 4 | Impairment of sumoylation increases $\beta$ Syn-GFP induced toxicity. (A) Spotting assay of $s m 3^{\text {ts }}$ mutant strain expressing $\beta$ Syn-GFP and 3xK/R-GFP at permissive $\left(25^{\circ} \mathrm{C} ;+\mathrm{SUMO}\right)$ or restrictive temperature $\left(30^{\circ} \mathrm{C}\right.$; $\left.-\mathrm{SUMO}\right)$. GAL1-driven synucleins are expressed from $2 \mu$ plasmid (oe-overexpression). GFP, expressed from the same promoter, is used as a control. Yeast cells were spotted in 10-fold dilutions on selection plates containing glucose (GAL1 promoter "OFF") or galactose (GAL1 promoter "ON"). (B) Spotting assay of smt3 ${ }^{\text {ts }}$ mutant strain expressing one copy (1x) of $\beta$ Syn-GFP or 3xK/R-GFP. Yeast cells, expressing GFP were used as a control. (C) Growth analysis of yeast cells from $(\mathbf{A}, \mathbf{B})$ in galactose-containing medium for $24 \mathrm{~h}$ at the indicated temperatures. (D) Growth rate of yeast cells in logarithmic phase. Significance of differences was calculated with One-way Anova test or $t$-test, relative to the GFP control $\left({ }^{* * *} p<0.01 ;{ }^{* * *} p<0.001\right.$;

$\left.{ }^{* * * *} p<0.0001 ; n=4\right)$. (E) Spotting assay of ulp $1^{\text {ts }}$ mutant strain expressing $\beta$ Syn-GFP and $3 \times K / R$-GFP from $2 \mu$ plasmid at $30^{\circ} \mathrm{C}$. (F) Live-cell fluorescence 
FIGURE 4 | Continued

microscopy of yeast cells expressing GAL 1-driven synuclein isoforms from $2 \mu$ plasmids in $s m t^{\text {ts }}$ strain and ulp $1^{\text {ts }}$ strain. Yeast cells, pre-grown to mid-log phase, were induced in galactose-containing medium and examined for aggregates at indicated temperatures and hours after induction. Scale bar $-5 \mu \mathrm{M}$. (G) Aggregate quantification of yeast cells, expressing synuclein-GFP isoforms in smt $3^{\text {ts }}$ strain at $25^{\circ} \mathrm{C}$ and $30^{\circ} \mathrm{C}$. For each strain, the number of cells displaying cytoplasmic foci is presented as percent of the total number of cells. The results are mean from at least four independent experiments \pm SD. (H) Aggregate quantification of yeast cells, expressing synuclein-GFP isoforms in ulp $7^{\text {ts }}$ strain $6 \mathrm{~h}$ and $24 \mathrm{~h}$ after induction of protein expression.

the proteasomal degradation of $\beta$ Syn. Up-regulation of the sumoylation pool promotes in addition the degradation by autophagy/vacuole.

\section{Downregulation of Sumoylation Increases the Accumulation of Ubiquitinated Cellular Proteins}

Sumoylation is involved in protein homeostasis by its interplay with the UPS (Liebelt and Vertegaal, 2016). It was examined, whether compromised degradation of $\beta$ Syn by the proteasome is connected to misregulation of UPS when cellular sumoylation is decreased. We followed the accumulation of ubiquitinated substrates in yeast cells in presence and absence of $\beta$ Syn expression and tested if downregulation of the cellular pool of functional SUMO affects the levels of ubiquitin conjugates. Immunoblotting analysis was performed with protein extracts from yeast cells, expressing $\beta$ Syn, K12/K85/K94R or empty vector control (Figure 7A). Inhibition of sumoylation in $s m t 3^{t s}$ strain revealed accumulation of ubiquitinated proteins, whereas up-regulation of the sumoylation pool by inhibition of the SUMO de-conjugation resulted in similar levels of ubiquitinated proteins as in W303 wild type yeast cells (Figure 7B). Expression of $\beta$ Syn variants did not affect the accumulation of ubiquitinated proteins in comparison to the empty vector control. Importantly, the steady-state levels of $\beta$ Syn variants differed between the yeast strains. Expression of $\beta$ Syn or $\mathrm{K} 12 / \mathrm{K} 85 / \mathrm{K} 94 \mathrm{R}$ in $s m t 3^{\text {ts }}$ cells resulted in significantly increased protein accumulation in comparison to the wild type W303 strain (Figure 7C), whereas up-regulation of the sumoylation in $u l p 1^{\text {ts }}$ cells decreased the protein levels. The increased protein levels correlated with accumulation of ubiquitinated substrates in smt3 $3^{\text {ts }}$ cells.

These findings showed that reduction of available functional SUMO has a strong impact on the steady-state levels of ubiquitin conjugates, including proteasomal degradation. This presumably leads to accumulation of soluble $\beta$ Syn protein in the cell and supports that sumoylation protects against $\beta$ Syn-induced toxicity by promoting the degradation of soluble as well as aggregated protein.

\section{DISCUSSION}

The budding yeast Saccharomyces cerevisiae was used as a prototypic eukaryotic cell to investigate the mechanism of $\beta$ Syn turnover and the effect of sumoylation on $\beta$ Syn-induced cytotoxicity, aggregation and protein stability. Accumulating evidence suggested that besides $\alpha$ Syn, also $\beta$ Syn is involved in the pathogenesis of aggregopathies such as PD. In the current study, we analyzed $\beta$ Syn lysine residues required for covalent attachment of SUMO, as well as the effect of the cellular sumoylation pool on $\beta$ Syn-induced toxicity, aggregate formation and stability.

Initial reports on $\beta$ Syn in double transgenic mice suggested that $\beta$ Syn is less prone to aggregation than $\alpha$ Syn and may counteract the $\alpha$ Syn aggregation (Hashimoto et al., 2001). Recent studies reported that $\beta$ Syn contributes to neuronal degeneration and suggest a possible toxic gain-offunction of $\beta$ Syn. It was shown that $\beta$ Syn forms Proteinase $\mathrm{K}$ resistant aggregates in primary cultured neurons and dopaminergic neurons in rat brains and to cause neurotoxicity (Taschenberger et al., 2013). Importantly, this effect was
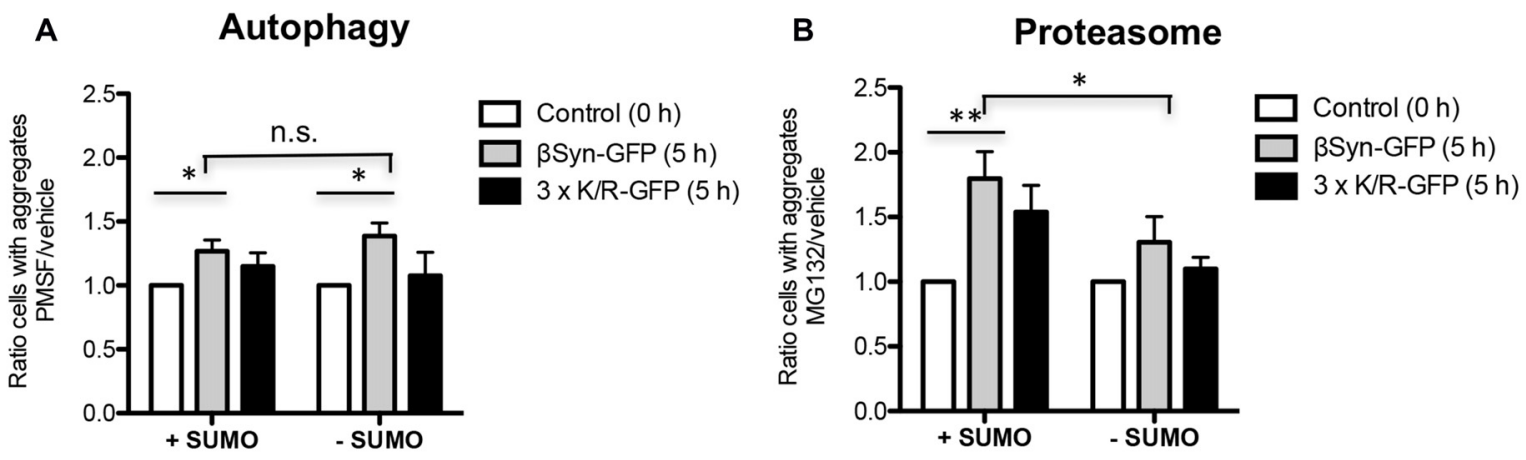

FIGURE 5 | $\beta$ Syn aggregate clearance after promoter shut-off. Quantification of cells displaying aggregates of $\beta$ Syn-GFP or 3xK/R-GFP upon inhibition of autophagy by phenylmethanesulfonyl fluoride (PMSF) (A) or proteasome by MG132 (B). Yeast cells were incubated in $2 \%$ galactose-containing media for $4 \mathrm{~h}$ either at permissive $\left(25^{\circ} \mathrm{C}\right.$; $\left.+\mathrm{SUMO}\right)$ or restrictive temperature $\left(30^{\circ} \mathrm{C}\right.$; -SUMO) and shifted to $2 \%$ glucose-containing media supplemented with $1 \mathrm{mM} \mathrm{PMSF}$ dissolved in EtOH $(\mathbf{A})$ or $75 \mu$ M MG132, dissolved in dimethyl sulfoxide (DMSO) (B). Control cells were supplemented with vehicles only (EtOH or DMSO). Cells with aggregates were counted after 5 h GAL1-promoter shut-off and presented as a ratio to the control. Significance of differences was calculated with $t$-test $\left({ }^{*} p<0.05 ;{ }^{* *} p<0.01 ; n=4\right)$. 


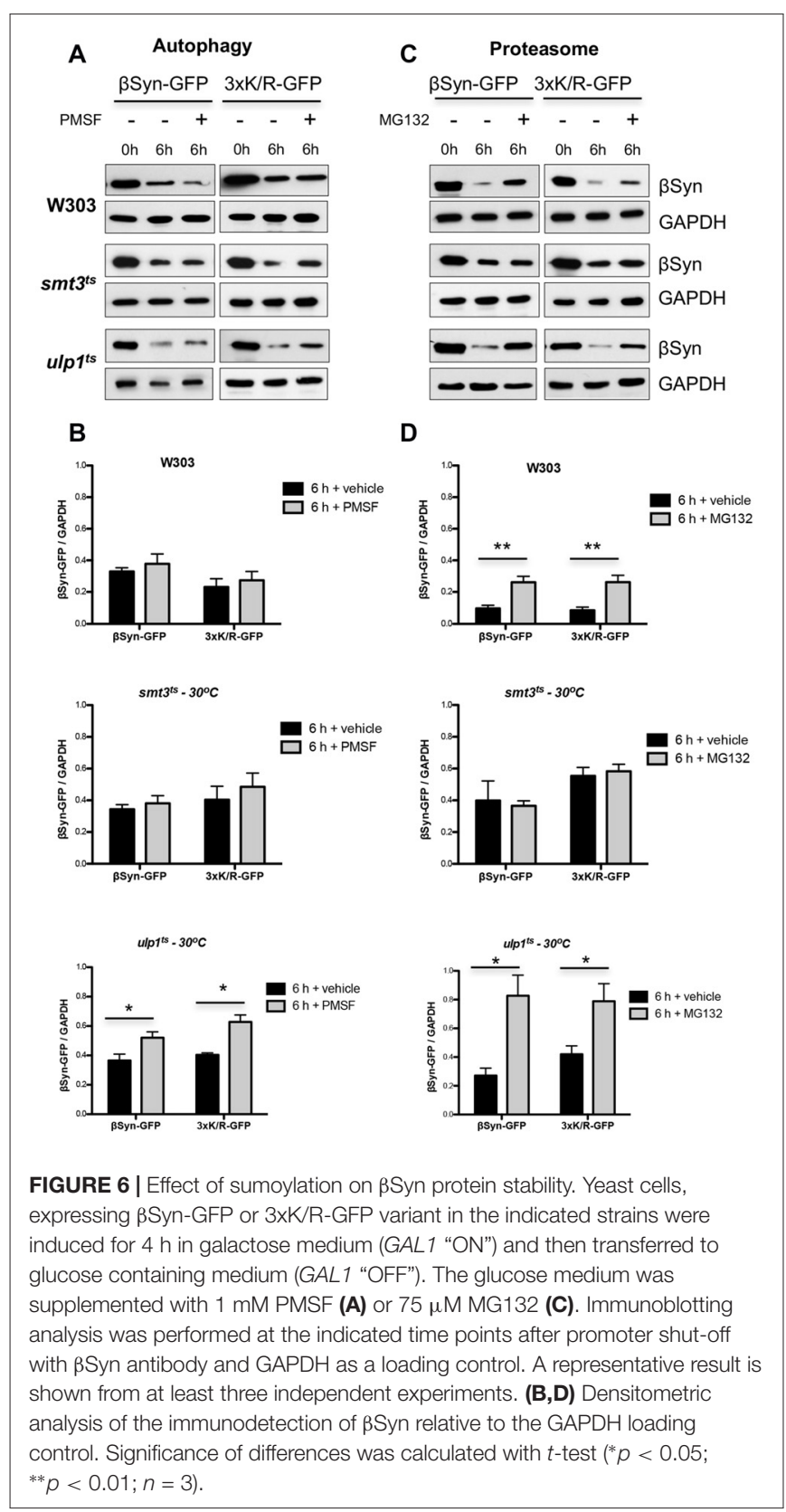

dependent on the accumulation of the protein over time and after 8 weeks of $\beta$ Syn overexpression, similar neurodegenerative effect to that of $\alpha$ Syn was observed. Another study reported on two mutations of $\beta$ Syn, P123H and V70M, linked to DLB that may stimulate neurodegeneration in transgenic mice by itself or via $\alpha$ Syn aggregation (Fujita et al., 2010). These studies reveal that $\beta$ Syn may possess gain-of-function pathogenic properties on its own or act synergistically with $\alpha$ Syn and that alteration of $\beta$ Syn levels in the cell might play a role in a broad range of synucleinopathies.

Budding yeast is an established model system to study the molecular mechanisms of PD and other synucleinopathies (Menezes et al., 2015; Popova et al., 2015). Expression of human $\alpha$ Syn in yeast induces growth inhibition and aggregate formation, similar to the pathology of the disease (Outeiro and Lindquist, 2003; Petroi et al., 2012). Recently, yeast was used to investigate the molecular mechanism of $\beta$ Syn-induced toxicity (Tenreiro et al., 2016). Expression of $\beta$ Syn was toxic and resulted in formation of cellular aggregates resembling the $\alpha$ Syn aggregates. $\beta$ Syn expression induced defects in similar pathways as $\alpha$ Syn, including ER-to-Golgi trafficking defects and increased oxidative stress. Importantly, co-expression of $\alpha$ Syn and $\beta$ Syn resulted in formation of heterodimers and enhanced toxicity due to additive accumulation of toxic protein species. Co-expression of $\alpha$ Syn and $\beta$ Syn strongly inhibited yeast vegetative growth, preventing the in-depth analysis of the molecular effects of $\alpha /$ BSyn co-expression (Tenreiro et al., 2016).

The increase in $\alpha$ Syn-mediated cytotoxicity is dose-dependent resulting in a threshold for toxicity (Outeiro and Lindquist, 2003; Petroi et al., 2012). The thresholds for $\beta$ Syn and $\alpha$ Syn mediated toxicity differed considerably in yeast. Three copies of the GAL1 promoter driven $\alpha$ Syn gene integrated into the yeast genome inhibited cellular growth (Petroi et al., 2012), but three copies with the same promoter for $\beta$ Syn were not sufficient for a significant growth effect. Overexpression of $\beta$ Syn significantly inhibited yeast growth and induced formation of cellular aggregation, similar to $\alpha$ Syn, corroborating that $\beta$ Syn has a higher threshold for toxicity and aggregation than $\alpha$ Syn.

PTMs including phosphorylation, ubiquitination, nitration, glycosylation, acetylation or sumoylation play an important role in regulation of $\alpha$ Syn function and stability (Giasson et al., 2000; Shimura et al., 2001; Fujiwara et al., 2002; Hasegawa et al., 2002; Dorval and Fraser, 2006; de Oliveira et al., 2017). Sumoylation can change sub-cellular protein localization, alter protein-protein interactions or change the solubility of the protein. Sumoylation is a dynamic process and the levels of sumoylated proteins are regulated by different stresses (Enserink, 2015). Sumoylation is directly involved in maintaining protein homeostasis and is closely linked to neurodegeneration, exhibiting a protective role against $\alpha$ Syn-induced toxicity and inclusion formation in yeast (Shahpasandzadeh et al., 2014).

Three lysine residues within consensus SUMO motifs are used for PTM of $\beta$ Syn in yeast. Inhibition of sumoylation at the single $\mathrm{K} 12$ site as well as at all three SUMO sites resulted in decreased aggregate formation, suggesting that sumoylation promotes aggregation. The results are based on mutagenesis analysis changing the codons for the consensus sumoylation sites of $\beta$ Syn. Cell growth or viability was not affected when sumoylation was inhibited. This supports that $\beta$ Syn mediated aggregate formation and cytotoxicity represent unlinked molecular functions. Global inhibition of the cellular sumoylation resulted in significant increase in $\beta$ Syn-induced toxicity without changes in aggregate formation. Functional sumoylation therefore protects yeast cells against $\beta$ Syn-induced toxicity without affecting the aggregate propensity of the protein (Figure 8). In line with our observations, expression of V70M and $\mathrm{P} 123 \mathrm{H} \beta$ Syn mutants, which are associated with sporadic and familial cases of DLB, increased the aggregate formation without enhancing the toxicity in yeast (Tenreiro et al., 2016). Accumulated BSyn may undergo additional PTMs such as 

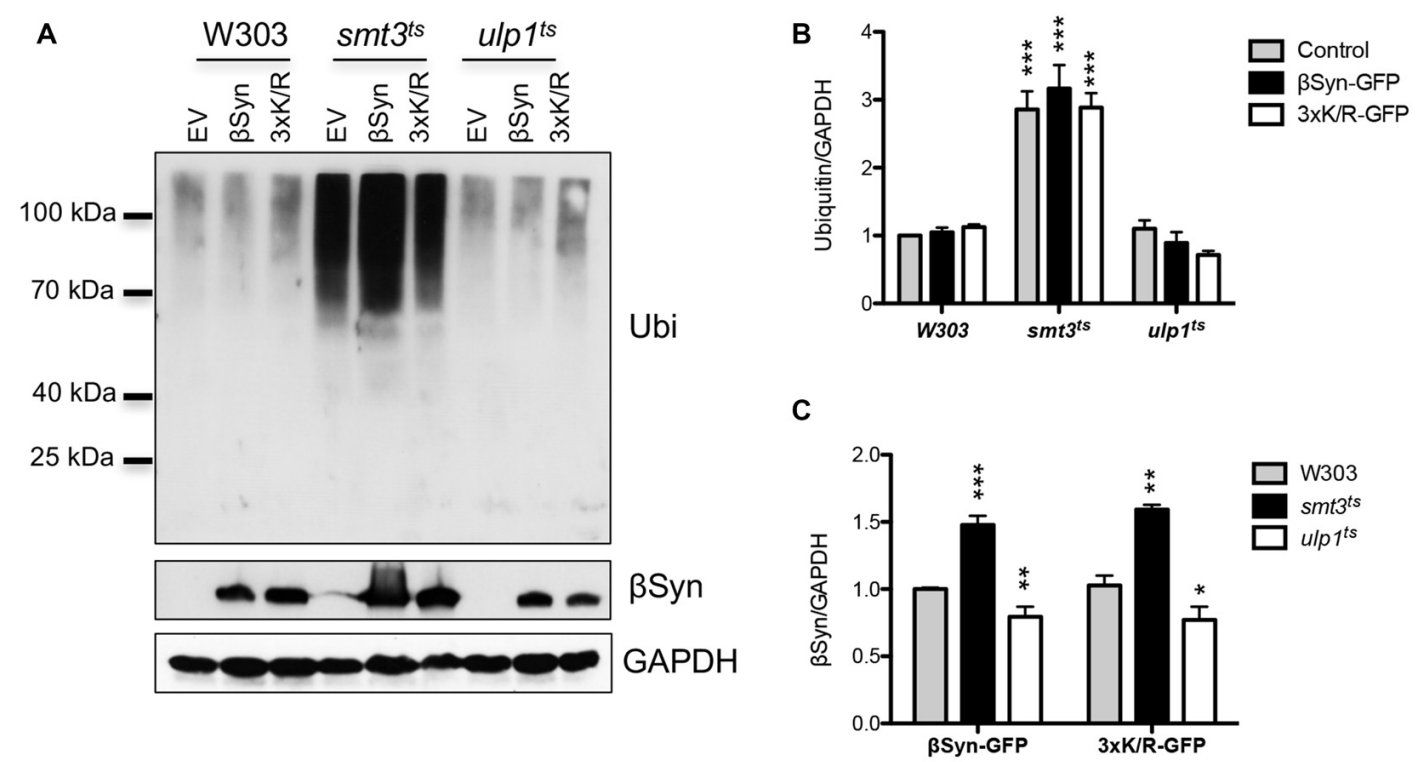

FIGURE 7 | Interplay between sumoylation and ubiquitination. (A) Western blot analysis of crude protein extracts from yeast cell, expressing $\beta$ Syn-GFP and $3 \times K / R-G F P$ mutant in W303, smt $3^{\text {ts }}$ and ulp $1^{\text {ts }}$ strains at $30^{\circ} \mathrm{C}$, probed with ubiquitin antibody, detecting poly-and mono-ubiquitinated proteins. The same membrane was stripped and probed with $\beta$ Syn antibody. GAPDH was used as a loading control. (B) Densitometric analysis of the immunodetection of ubiquitin or $\beta S y n$ (C), relative to the GAPDH loading control. Significance of differences was calculated with $t$-test $\left({ }^{* * *} p<0.001 ; * * p<0.01 ;{ }^{*} p<0.05\right.$ vs. W303 wild type background; $n=3$ ).

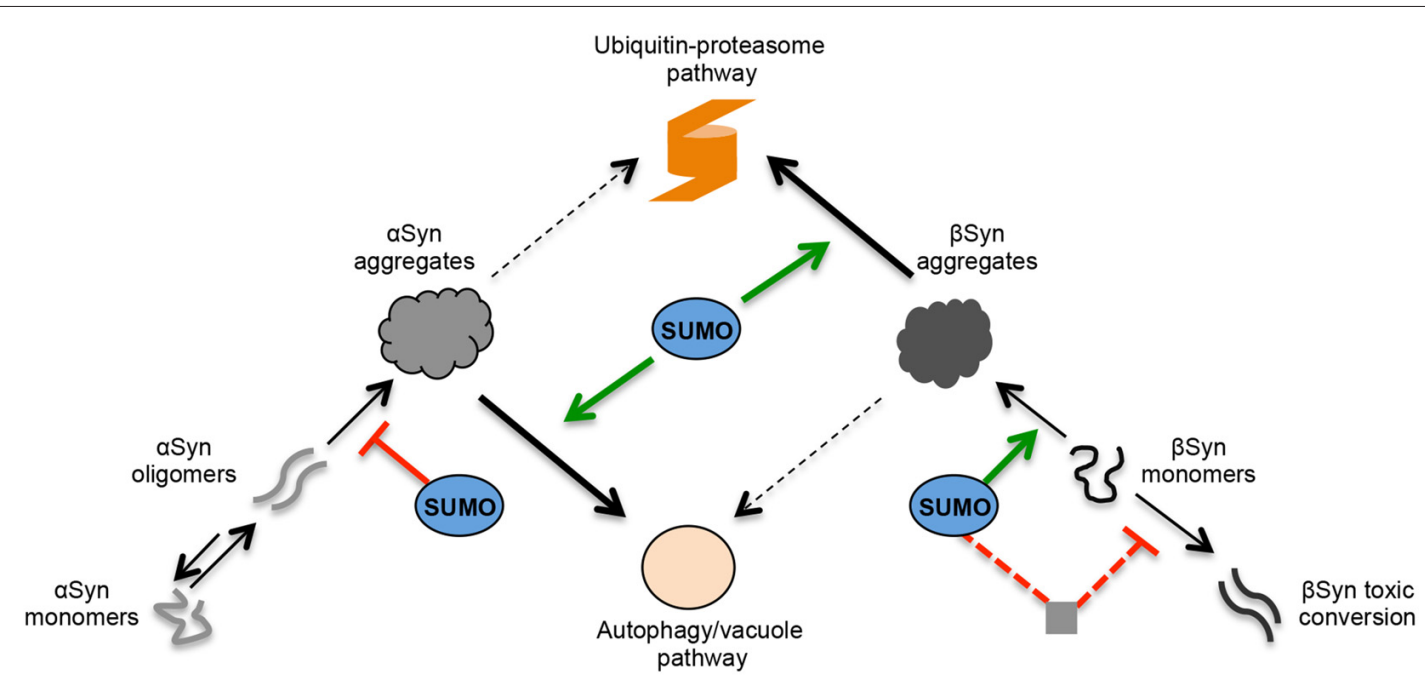

FIGURE 8 | Role of SUMO in the regulation of $\alpha$ Syn and $\beta$ Syn turnover and toxicity in yeast. Schematic representation of $\alpha$ Syn and $\beta$ Syn aggregation pathways. Under pathological conditions, $\alpha$ Syn can undergo oligomerization. A dynamic equilibrium exists between monomeric and multimeric forms of $\alpha$ Syn. The oligomeric species represent intermediates of the aggregation process and are suggested to be the most toxic forms of $\alpha$ Syn. SUMO exhibits a protective role against $\alpha$ Syn-induced toxicity. Sumoylation increases the solubility $\alpha$ Syn and decreases the aggregation of the protein. In contrast, $\beta$ Syn aggregate formation and cytotoxicity are part of different molecular mechanisms. A fraction of accumulated $\beta$ Syn might gradually undergo structural conversion and form toxic oligomers or fibrils. In contrast to $\alpha$ Syn, these might not be intermediate species in the aggregation process but might be part of an independent molecular pathway. Sumoylation of $\beta$ Syn promotes the aggregate formation of the protein without affecting the cytotoxicity. The presence of functional cellular sumoylation machinery protects against $\beta$ Syn toxicity independently of $\beta$ Syn sumoylation. Sumoylation of additional target proteins or cellular pathways might be involved in the cytoprotection by inhibiting the formation of $\beta$ Syn toxic species. $\alpha$ Syn and $\beta$ Syn aggregates are cleared predominantly by two different pathways. The main pathway for $\alpha$ Syn aggregate clearance is autophagy, whereas ubiquitin-proteasome system (UPS) is the major degradation pathway for $\beta$ Syn aggregates. Autophagy/vacuolar pathway has a minor contribution to $\beta$ Syn aggregate clearance. Presence of functional SUMO protects against $\beta$ Syn as well as $\alpha$ Syn toxicity by promoting the degradation of the proteins. Sumoylated $\alpha$ Syn is primarily targeted to the autophagy pathway, whereas presence of functional SUMO promotes the degradation of $\beta$ Syn monomers and $\beta$ Syn aggregates by the ubiquitin-proteasome pathway. 
phosphorylation or acetylation and gain pathogenic properties. A fraction of $\beta$ Syn might adopt a different structure and form toxic oligomers or fibrils. In contrast to $\alpha$ Syn this might not necessarily lead to aggregates. The cellular environment might be relevant, because it is known that $\beta$ Syn can form fibrils at mild acidic $\mathrm{pH}$ as a result of $\mathrm{pH}$ dysregulation due to oxidative stress or in acidic organelles such as endosomes or lysosomes/vacuoles (Moriarty et al., 2017). Alteration of $\beta$ Syn may enhance synergistically the toxicity of $\alpha$ Syn and promote PD pathology. Another possible explanation is that the disintegration between toxicity and aggregation is due to the co-existence of toxic aggregates and non-toxic "protective" aggregates. Sumoylation might protect against cytotoxicity by promoting the conversion of toxic into protective aggregates.

The protective role of sumoylation against $\alpha$ Syn-induced toxicity is significantly different from $\beta S y n$. Sumoylation increases the solubility $\alpha$ Syn and thereby decreases the aggregation of the protein (Krumova et al., 2011). In contrast to $\beta$ Syn, direct modification of $\alpha$ Syn by SUMO at the conserved modification sites K96 and K102 reduced the formation of inclusions and simultaneously protected against cytotoxicity. Therefore, sumoylation promotes $\beta$ Syn but reduces $\alpha$ Syn aggregation. In contrast, the cellular sumoylation machinery is equally important for protection against $\beta$ Syn as well as $\alpha$ Syn, because inhibition of cellular sumoylation had a similar negative impact on growth of yeast cells expressing either $\beta$ Syn or $\alpha$ Syn (Shahpasandzadeh et al., 2014).

One of the major factors that lead to $\mathrm{PD}$ pathogenesis is decreased degradation of $\alpha$ Syn protein by one of the two major proteolytic systems-the autophagy/lysosome system or UPS (Xilouri et al., 2013; Vilchez et al., 2014). This contributes to increased protein levels and aggregation. Yeast has been extensively used for examination of $\alpha$ Syn degradation due to the high conservation of functions and pathways, involved in protein quality control between yeast and higher eukaryotes, including humans. Autophagy is the major pathway for $\alpha$ Syn aggregate clearance in yeast (Petroi et al., 2012; Tenreiro et al., 2014). Sumoylation of $\alpha$ Syn promoted aggregate clearance by autophagy, whereas phosphorylation at S129 triggered increased ubiquitination and degradation of the protein by the UPS (Shahpasandzadeh et al., 2014). Here, we demonstrated that UPS is the major degradation pathway, responsible for clearance of $\beta$ Syn aggregates. Sumoylation promoted the aggregate clearance by the UPS significantly, whereas autophagy/vacuolar pathway had a minor contribution to $\beta$ Syn aggregate clearance that was not dependent on a functional sumoylation pool (Figure 8). These results indicate that $\alpha$ Syn and $\beta$ Syn aggregates have different mechanisms for aggregate clearance.

The effect of SUMO on $\beta$ Syn protein stability is consistent with the aggregate clearance assays. Inhibition of the proteasome significantly increased the level of $\beta$ Syn. Downregulation of sumoylation stabilized the $\beta$ Syn protein and abolished its degradation through the UPS, whereas upregulation of the sumoylation had an opposite effect on protein stability. Similarly, sumoylation promotes the degradation of soluble $\alpha$ Syn monomers in yeast that occurs through both degradation pathways (Shahpasandzadeh et al., 2014). These findings highlight the complex regulative role of SUMO in balancing the protein levels of $\alpha$ Syn and $\beta$ Syn.

Autophagy and the ubiquitin-dependent degradation pathways do not act independently from each other. In the process of selective autophagy, ubiquitination can target proteins not only to the 26S-proteasome but also for autophagic degradation (Kirkin et al., 2009). Inactive 26S-proteasomes can be degraded by the autophagy in a newly discovered pathway termed "proteaphagy" (autophagy of proteasomes), initially described in plants and yeast (Marshall et al., 2015, 2016) and recently reported in mammalian cells (Cohen-Kaplan et al., 2016). Inactivation of UPS is one of the major causes for PD pathology. A proposed mechanism for UPS dysfunction is the direct binding of soluble oligomeric or aggregated species of $\alpha$ Syn with the 26S-proteasome that inhibit its activity (Xilouri et al., 2013). Thus, a possible scenario for $\alpha$ Syn clearance is degradation of the protein together with the inactive proteasomes via the proteaphagy pathway. $\beta$ Syn has no direct effect on the $26 \mathrm{~S}$ ubiquitin-dependent degradation and does not bind to the 26S proteasome (Snyder et al., 2005). Thus, higher protein loads of $\beta$ Syn can be processed by the 26S-proteasome. This might account for the different involvement of the two degradation pathways in the clearance of $\alpha$ Syn and $\beta$ Syn.

An important contribution of SUMO to protein homeostasis is its interplay with the UPS (Liebelt and Vertegaal, 2016). SUMO-acceptor lysine residues can be targets for ubiquitin conjugation. Thus, sumoylation can directly antagonize the degradation by UPS by a competition with ubiquitin at the same lysine residues, as first shown for IкB- $\alpha$ (Desterro et al., 1998), or can function cooperatively with ubiquitination in a sequential cycle that regulates the function, localization and stability of the protein, as reported for PCNA (Hoege et al., 2002). SUMO can also function as a recognition signal for SUMO-targeted ubiquitin ligases, thus mediating ubiquitin-dependent degradation by the proteasome (Uzunova et al., 2007; Tatham et al., 2008). Downregulation of sumoylation in our studies resulted in significant accumulation of ubiquitinated conjugates and increased levels of $\beta$ Syn protein in the cell. Expression of $\beta$ Syn did not affect the steady-state levels of ubiquitin conjugates, consistent with previous findings (Snyder et al., 2005). This indicates that elevated levels of soluble $\beta S y n$ may account for the increased $\beta S y n$-induced toxicity and sumoylation has a protective role by promoting the degradation of the protein.

The complex functional interaction of SUMO and the UPS may also contribute to off-target effects of sumoylation on $\beta$ Syn protein stability and toxicity. Sumoylation might regulate protein stability or function of additional target proteins and thus indirectly affect the cytotoxicity of $\beta S y n$ (Figure 8). The off-target effect of SUMO may co-exist with the direct effect of sumoylation on $\beta$ Syn toxicity. It should be noted that the analysis of temperature sensitive mutant strains can evoke additional indirect effects on $\beta$ Syn protein quality control.

In this study, we provide evidence that the molecular basis of $\beta S y n$-induced cytotoxicity and accumulation in the cell is not directly linked to $\beta$ Syn aggregate formation. 
Aggregate formation and cytotoxicity are both linked to sumoylation. Sumoylation determines the accumulation of $\beta$ Syn and therefore its cytotoxicity. Our data strongly support that the major molecular pathway involved in $\beta$ Syn turnover and clearance of soluble as well as aggregated proteins is the $26 \mathrm{~S}$ proteasome.

\section{AUTHOR CONTRIBUTIONS}

BP and GHB designed the research. BP, AK, PA, JM and DW performed and analyzed the experiments. BP and GHB wrote the manuscript, with contributions from AK.

\section{REFERENCES}

Alberti, S., Halfmann, R., and Lindquist, S. (2010). Biochemical, cell biological, and genetic assays to analyze amyloid and prion aggregation in yeast. Methods Enzymol. 470, 709-734. doi: 10.1016/s0076-6879(10) 70030-6

Cohen-Kaplan, V., Livneh, I., Avni, N., Fabre, B., Ziv, T., Kwon, Y. T., et al. (2016). p62- and ubiquitin-dependent stress-induced autophagy of the mammalian $26 \mathrm{~S}$ proteasome. Proc. Natl. Acad. Sci. U S A 113, E7490-E7499. doi: 10.1073/pnas. 1615455113

de Oliveira, R. M., Vicente Miranda, H., Francelle, L., Pinho, R., Szegö, É. M., Martinho, R., et al. (2017). The mechanism of sirtuin 2-mediated exacerbation of $\alpha$-synuclein toxicity in models of Parkinson disease. PLoS Biol. 15:e2000374. doi: 10.1371/journal.pbio.2000374

Desterro, J. M., Rodriguez, M. S., and Hay, R. T. (1998). SUMO-1 modification of $\mathrm{I} \kappa \mathrm{B} \alpha$ inhibits NF-кB activation. Mol. Cell 2, 233-239. doi: 10.1016/S10972765(00)80133-1

Dieckhoff, P., Bolte, M., Sancak, Y., Braus, G. H., and Irniger, S. (2004). Smt3/SUMO and Ubc9 are required for efficient APC/C-mediated proteolysis in budding yeast. Mol. Microbiol. 51, 1375-1387. doi: 10.1046/j.1365-2958. 2003.03910.x

Dorval, V., and Fraser, P. E. (2006). Small ubiquitin-like modifier (SUMO) modification of natively unfolded proteins tau and $\alpha$-synuclein. J. Biol. Chem. 281, 9919-9924. doi: 10.1074/jbc.M510127200

Ducas, V. C., and Rhoades, E. (2012). Quantifying interactions of $\beta$-synuclein and $\gamma$-synuclein with model membranes. J. Mol. Biol. 423, 528-539. doi: 10.1016/j. jmb.2012.08.008

Eckermann, K. (2013). SUMO and Parkinson's disease. Neuromolecular Med. 15, 737-759. doi: 10.1007/s12017-013-8259-5

Enserink, J. M. (2015). Sumo and the cellular stress response. Cell Div. 10:4. doi: 10.1186/s13008-015-0010-1

Fan, Y., Limprasert, P., Murray, I. V. J., Smith, A. C., Lee, V. M. Y., Trojanowski, J. Q., et al. (2006). $\beta$-synuclein modulates $\alpha$-synuclein neurotoxicity by reducing $\alpha$-synuclein protein expression. Hum. Mol. Genet. 15, 3002-3011. doi: 10.1093/hmg/ddl242

Fujita, M., Sugama, S., Sekiyama, K., Sekigawa, A., Tsukui, T., Nakai, M., et al. (2010). A $\beta$-synuclein mutation linked to dementia produces neurodegeneration when expressed in mouse brain. Nat. Commun. 1:110. doi: $10.1038 /$ ncomms1101

Fujiwara, H., Hasegawa, M., Dohmae, N., Kawashima, A., Masliah, E., Goldberg, M. S., et al. (2002). $\alpha$-Synuclein is phosphorylated in synucleinopathy lesions. Nat. Cell Biol. 4, 160-164. doi: 10.1038/ncb748

George, J. M. (2002). The synucleins. Genome Biol. 3, reviews3002.1-reviews 3002.6 .

Giasson, B. I., Duda, J. E., Murray, I. V., Chen, Q., Souza, J. M., Hurtig, H. I., et al. (2000). Oxidative damage linked to neurodegeneration by selective $\alpha$-synuclein nitration in synucleinopathy lesions. Science 290, 985-989. doi: 10.1126/science.290.5493.985

Gietz, D., St Jean, A., Woods, R. A., and Schiestl, R. H. (1992). Improved method for high efficiency transformation of intact yeast cells. Nucleic Acids Res. 20:1425. doi: 10.1093/nar/20.6.1425

\section{FUNDING}

This work was funded by the Deutsche Forschungsgemeinschaft (DFG) Research Center Nanoscale Microscopy and Molecular Physiology of the Brain (CNMPB), Göttingen, Germany.

\section{ACKNOWLEDGMENTS}

We thank Maria Meyer and Katharina Ziese-Kubon for excellent technical assistance. We thank Kai Heimel for reading of the manuscript.

Guthrie, C., and Fink, G. R. (1991). Guide to yeast genetics and molecular biology. Methods Enzymol. 194, 1-863. doi: 10.1016/s0076-6879(00)x0276-5

Hasegawa, M., Fujiwara, H., Nonaka, T., Wakabayashi, K., Takahashi, H., Lee, V. M., et al. (2002). Phosphorylated $\alpha$-synuclein is ubiquitinated in $\alpha$ synucleinopathy lesions. J. Biol. Chem. 277, 49071-49076. doi: 10.1074/jbc. M208046200

Hashimoto, M., Rockenstein, E., Mante, M., Mallory, M., and Masliah, E. (2001). $\beta$-Synuclein inhibits $\alpha$-synuclein aggregation: a possible role as an anti-parkinsonian factor. Neuron 32, 213-223. doi: 10.1016/S08966273(01)00462-7

Hoege, C., Pfander, B., Moldovan, G.-L. L., Pyrowolakis, G., and Jentsch, S. (2002). RAD6-dependent DNA repair is linked to modification of PCNA by ubiquitin and SUMO. Nature 419, 135-141. doi: 10.1038/nature00991

Kalia, L. V., and Lang, A. E. (2015). Parkinson's disease. Lancet 386, 896-912. doi: 10.1016/S0140-6736(14)61393-3

Kirkin, V., McEwan, D. G., Novak, I., and Dikic, I. (2009). A role for ubiquitin in selective autophagy. Mol. Cell 34, 259-269. doi: 10.1016/j.molcel.2009.04.026

Kleinknecht, A., Popova, B., Lázaro, D. F., Pinho, R., Valerius, O., Outeiro, T. F., et al. (2016). C-terminal tyrosine residue modifications modulate the protective phosphorylation of serine 129 of $\alpha$-synuclein in a yeast model of Parkinson's disease. PLoS Genet. 12:e1006098. doi: 10.1371/journal.pgen. 1006098

Krüger, R., Kuhn, W., Müller, T., Woitalla, D., Graeber, M., Kösel, S., et al. (1998). Ala30Pro mutation in the gene encoding $\alpha$-synuclein in Parkinson's disease Nat. Genet. 18, 106-108. doi: 10.1038/ng0298-106

Krumova, P., Meulmeester, E., Garrido, M., Tirard, M., Hsiao, H. H., Bossis, G., et al. (2011). Sumoylation inhibits $\alpha$-synuclein aggregation and toxicity. J. Cell Biol. 194, 49-60. doi: 10.1083/jcb.201010117

Li, J., Henning Jensen, P., and Dahlström, A. (2002). Differential localization of $\alpha-, \beta$ - and $\gamma$-synucleins in the rat CNS. Neuroscience 113, 463-478. doi: 10.1016/s0306-4522(02)00143-4

Li, S.-J., and Hochstrasser, M. (1999). A new protease required for cell-cycle progression in yeast. Nature 398, 246-251. doi: 10.1038/18457

Liebelt, F., and Vertegaal, A. C. O. (2016). Ubiquitin-dependent and independent roles of SUMO in proteostasis. Am. J. Physiol. Cell Physiol. 311, C284-C296. doi: 10.1152/ajpcell.00091.2016

Marshall, R. S., Li, F., Gemperline, D. C., Book, A. J., and Vierstra, R. D. (2015). Autophagic degradation of the $26 \mathrm{~S}$ proteasome is mediated by the dual ATG8/ubiquitin receptor RPN10 in arabidopsis. Mol. Cell 58, 1053-1066. doi: 10.1016/j.molcel.2015.04.023

Marshall, R. S., McLoughlin, F., and Vierstra, R. D. (2016). Autophagic turnover of inactive $26 \mathrm{~S}$ proteasomes in yeast is directed by the ubiquitin receptor Cue 5 and the Hsp42 chaperone. Cell Rep. 16, 1717-1732. doi: 10.1016/j.celrep. 2016.07.015

Mbefo, M. K., Paleologou, K. E., Boucharaba, A., Oueslati, A., Schell, H., Fournier, M., et al. (2010). Phosphorylation of synucleins by members of the Polo-like kinase family. J. Biol. Chem. 285, 2807-2822. doi: 10.1074/jbc.M109. 081950

Menezes, R., Tenreiro, S., Macedo, D., Santos, C. N., and Outeiro, T. F. (2015). From the baker to the bedside: yeast models of Parkinson's disease. Microb. Cell 2, 262-279. doi: 10.15698/mic2015.08.219 
Mori, F., Tanji, K., Yoshimoto, M., Takahashi, H., and Wakabayashi, K. (2002). Immunohistochemical comparison of $\alpha$ - and $\beta$-synuclein in adult rat central nervous system. Brain Res. 941, 118-126. doi: 10.1016/s0006-8993(02)02643-4

Moriarty, G. M., Olson, M. P., Atieh, T. B., Janowska, M. K., Khare, S. D., and Baum, J. (2017). A pH dependent switch promotes $\beta$-synuclein fibril formation via glutamate residues. J. Biol. Chem. 292, 16368-16379. doi: 10.1074/jbc. M117.780528

Mumberg, D., Müller, R., Funk, M., Müller, R., and Funk, M. (1994). Regulatable promoters of Saccharomyces cerevisiae: comparison of transcriptional activity and their use for heterologous expression. Nucleic Acids Res. 22, 5767-5768. doi: 10.1093/nar/22.25.5767

Nakajo, S., Tsukada, K., Omata, K., Nakamura, Y., and Nakaya, K. (1993). A new brain-specific $14-\mathrm{kDa}$ protein is a phosphoprotein. Its complete amino acid sequence and evidence for phosphorylation. Eur. J. Biochem. 217, 1057-1063. doi: 10.1111/j.1432-1033.1993.tb18337.x

Ohtake, H., Limprasert, P., Fan, Y., Onodera, O., Kakita, A., Takahashi, H., et al. (2004). $\beta$-synuclein gene alterations in dementia with Lewy bodies. Neurology 63, 805-811. doi: 10.1212/01.WNL.0000139870.14385.3C

Outeiro, T. F., and Lindquist, S. (2003). Yeast cells provide insight into $\alpha$-synuclein biology and pathobiology. Science 302, 1772-1775. doi: 10.1126/science. 1090439

Petroi, D., Popova, B., Taheri-Talesh, N., Irniger, S., Shahpasandzadeh, H., Zweckstetter, M., et al. (2012). Aggregate clearance of $\alpha$-synuclein in Saccharomyces cerevisiae depends more on autophagosome and vacuole function than on the proteasome. J. Biol. Chem. 287, 27567-27579. doi: 10.1074/jbc.M112.361865

Polymeropoulos, M. H., Lavedan, C., Leroy, E., Ide, S. E., Dehejia, A., Dutra, A., et al. (1997). Mutation in the $\alpha$-synuclein gene identified in families with Parkinson's disease. Science 276, 2045-2047. doi: 10.1126/science.276. 5321.2045

Popova, B., Kleinknecht, A., and Braus, G. (2015). Posttranslational modifications and clearing of $\alpha$-synuclein aggregates in yeast. Biomolecules 5, 617-634. doi: 10.3390/biom5020617

Shahpasandzadeh, H., Popova, B., Kleinknecht, A., Fraser, P. E., Outeiro, T. F., and Braus, G. H. (2014). Interplay between sumoylation and phosphorylation for protection against $\alpha$-synuclein inclusions. J. Biol. Chem. 289, 31224-31240. doi: $10.1074 /$ jbc.M114.559237

Shimura, H., Schlossmacher, M. G., Hattori, N., Frosch, M. P., Trockenbacher, A., Schneider, R., et al. (2001). Ubiquitination of a new form of $\alpha$-synuclein by parkin from human brain: implications for Parkinson's disease. Science 293, 263-269. doi: 10.1126/science.1060627

Sikorski, R. S., and Hieter, P. (1989). A system of shuttle vectors and yeast host strains designed for efficient manipulation of DNA in Saccharomyces cerevisiae. Genetics 122, 19-27.

Singleton, A. B., Farrer, M., Johnson, J., Singleton, A., Hague, S., Kachergus, J., et al. (2003). $\alpha$-Synuclein locus triplication causes Parkinson's disease. Science 302:841. doi: 10.1126/science. 1090278

Snyder, H., Mensah, K., Hsu, C., Hashimoto, M., Surgucheva, I. G., Festoff, B., et al. (2005). $\beta$-Synuclein reduces proteasomal inhibition by $\alpha$-synuclein but not $\gamma$-synuclein. J. Biol. Chem. 280, 7562-7569. doi: 10.1074/jbc.M412887200

Spillantini, M. G., Crowther, R. A., Jakes, R., Hasegawa, M., and Goedert, M. (1998). $\alpha$-Synuclein in filamentous inclusions of Lewy bodies from Parkinson's disease and dementia with lewy bodies. Proc. Natl. Acad. Sci. U S A 95, 6469-6473. doi: 10.1073/pnas.95.11.6469

Sung, Y.-H., and Eliezer, D. (2006). Secondary structure and dynamics of micelle bound $\beta$ - and $\gamma$-synuclein. Protein Sci. 15, 1162-1174. doi: 10.1110/ps. 051803606
Taschenberger, G., Toloe, J., Tereshchenko, J., Akerboom, J., Wales, P., Benz, R., et al. (2013). $\beta$-synuclein aggregates and induces neurodegeneration in dopaminergic neurons. Ann. Neurol. 74, 109-118. doi: 10.1002/ana. 23905

Tatham, M. H., Geoffroy, M.-C., Shen, L., Plechanovova, A., Hattersley, N., Jaffray, E. G., et al. (2008). RNF4 is a poly-SUMO-specific E3 ubiquitin ligase required for arsenic-induced PML degradation. Nat. Cell Biol. 10, 538-546. doi: $10.1038 /$ ncb1716

Tenreiro, S., Reimão-Pinto, M. M., Antas, P., Rino, J., Wawrzycka, D., Macedo, D., et al. (2014). Phosphorylation modulates clearance of $\alpha$-synuclein inclusions in a yeast model of Parkinson's disease. PLoS Genet. 10:e1004302. doi: 10.1371/journal.pgen.1004302

Tenreiro, S., Rosado-Ramos, R., Gerhardt, E., Favretto, F., Magalhães, F., Popova, B., et al. (2016). Yeast reveals similar molecular mechanisms underlying $\alpha$ - and $\beta$-synuclein toxicity. Hum. Mol. Genet. 25, 275-290. doi: $10.1093 / \mathrm{hmg} / \mathrm{ddv} 470$

Uversky, V. N., Li, J., Souillac, P., Millett, I. S., Doniach, S., Jakes, R., et al. (2002). Biophysical properties of the synucleins and their propensities to fibrillate: inhibition of $\alpha$-synuclein assembly by $\beta$ - and $\gamma$-synucleins. J. Biol. Chem. 277, 11970-11978. doi: 10.1074/jbc.M109541200

Uzunova, K., Göttsche, K., Miteva, M., Weisshaar, S. R., Glanemann, C., Schnellhardt, M., et al. (2007). Ubiquitin-dependent proteolytic control of SUMO conjugates. J. Biol. Chem. 282, 34167-34175. doi: 10.1074/jbc. M706505200

Vilchez, D., Saez, I., and Dillin, A. (2014). The role of protein clearance mechanisms in organismal ageing and age-related diseases. Nat. Commun. 5:5659. doi: $10.1038 /$ ncomms6659

Villar-Piqué, A., Lopes da Fonseca, T., and Outeiro, T. F. (2015). Structure, function and toxicity of $\alpha$-synuclein: the Bermuda triangle in synucleinopathies. J. Neurochem. 139, 240-255. doi: 10.1111/jnc. 13249

Webb, J. L., Ravikumar, B., Atkins, J., Skepper, J. N., and Rubinsztein, D. C. (2003). $\alpha$-Synuclein is degraded by both autophagy and the proteasome. J. Biol. Chem. 278, 25009-25013. doi: 10.1074/jbc.M300227200

Wei, J., Fujita, M., Nakai, M., Waragai, M., Watabe, K., Akatsu, H., et al. (2007). Enhanced lysosomal pathology caused by $\beta$-synuclein mutants linked to dementia with Lewy bodies. J. Biol. Chem. 282, 28904-28914. doi: 10.1074/jbc.M703711200

Xilouri, M., Brekk, O. R., and Stefanis, L. (2013). $\alpha$-synuclein and protein degradation systems: a reciprocal relationship. Mol. Neurobiol. 47, 537-551. doi: 10.1007/s12035-012-8341-2

Zarranz, J. J., Alegre, J., Gómez-Esteban, J. C., Lezcano, E., Ros, R., Ampuero, I., et al. (2004). The new mutation, E46K, of $\alpha$-synuclein causes Parkinson and Lewy body dementia. Ann. Neurol. 55, 164-173. doi: 10.1002/ana. 10795

Conflict of Interest Statement: The authors declare that the research was conducted in the absence of any commercial or financial relationships that could be construed as a potential conflict of interest.

Copyright (c) 2018 Popova, Kleinknecht, Arendarski, Mischke, Wang and Braus. This is an open-access article distributed under the terms of the Creative Commons Attribution License (CC BY). The use, distribution or reproduction in other forums is permitted, provided the original author(s) and the copyright owner are credited and that the original publication in this journal is cited, in accordance with accepted academic practice. No use, distribution or reproduction is permitted which does not comply with these terms. 